\section{Diagrammatic Manifestos: A Method for Studying the Fluidity of Gender in the Production of Fashion Photography}

By Floriane Misslin

\section{Abstract}

This sociological research studies how fashion editors, art directors, and photographers make the fluidity of gender more visible within an industry established on the binary womenswear / menswear. It addresses gender fluid practices as a questioning of the conditions in which relations between body and dress are made systematic. The research has identified some of the restrictions faced when producing gender fluid fashion imagery, and highlighted the alternative solutions that originate from these limitations. This paper proposes to apply live and inventive methodological approaches to fashion studies. The design of my methodology was concerned with its capacity to study a subject still mostly understood through a binary ontology. Consequently, the "Diagrammatic Manifestos" is a research method attentive to the conditions in which relations can be made different, rather than identical, to dominant gender ideals. Throughout the series of interviews, diagrams were operated as analytical devices to graphically reorganize transcripts into manifestos. The diagrams' forms were made responsive to the differences in each participants' narrative and reveal how their individual experiences of gender affect the images they produce.

\title{
KEYWORDS:
}

GENDER FLUIDITY

FASHION PHOTOGRAPHY

DIAGRAMS 


\section{INTRODUCTION}

Across the conversations I had with producers of fashion photography in London, a gender fluid approach to fashion has been mentioned as something missing in both the clothing industry and its visual culture. The practices of the photographers, art directors, and editors who participated in this research challenge the way that the fashion industry systemizes experiences of identity-making exclusively through the categories of womenswear and menswear. Drawing on Muñoz's ideas of queer utopias (2009), I identified the images they produce as temporal disorganizations presenting the fashion system as changeable. This research approaches fashion photography as an "instrument of critique" (Titton, 2016) through which diverse relations to gender can be made visible at the surface of fashion media. In this paper, I reflect on the Diagrammatic Manifestos, a method I designed and implemented to probe how gender fluid practices of fashion photography can be described through sociological research methods.

Sociological studies on the production of fashion photography have until now primarily looked into the functioning of established markets and institutions that dominantly reproduce binary representations of gender ideals (Aspers, 2001; Aspers and Godart, 2013; Budgeon, 2013; Crane, 1999; Crane and Bovone, 2006; Entwistle and Mears, 2013; Godart and Mears, 2009; Moeran, 2006; Ruggerone, 2006; Sadre-Orafai, 2016). In order to elaborate on the way gender is understood in social research (Linstead and Brewis, 2004), this research focuses on studying media of smaller scale that tend to be more critical of the fashion industry's dominant discourses (Lynge-Jorlén, 2012; Titton, 2016). This paper addresses my attempt to design a research method capable of engaging with accounts that diverge from binary understandings of gender.

\section{It then raises the question: how can research methods highlight complex relations to gender without upholding binary bias?}

I designed my methodology following the perspective of live methods proposed by Back and Puwar (2012). It proposes involving more attention to the sensory and the personal with creative methods in sociological research. I suggest that live methods can be beneficial to fashion studies for grasping the multi-sensory modalities through which we experience fashion and gender (Barry, 2017; Granata, 2012; Jenss, 2016). My methodology intervened as a reflective process in which myself and fashion photography producers cooperated to analyze, question, and formulate the political motivations of their practices and the impact they have on both the industry and its audience. 


\section{The method of the Diagrammatic Manifestos consists of co-producing a manifesto with each participant through a series of interviews.}

It uses the format of the manifesto as a short statement about one's practice that can be shared publicly and circulated widely. I used diagrams to analyze the interview transcripts and make my interpretations visible to the participants throughout the research process. Importantly, the diagrams facilitated a graphic reorganization of the data that emphasized the differences between each participants' way of describing their relation to gender.

In the first section of this paper, I situate my research in existing studies on fashion photography and Deleuzian perspectives on gender. The second section is divided in five subsections. After developing the intention of my methodology, I define my research sample and draw a brief description of my diagramming process. I then reflect on my use of diagrams as devices; firstly, as analytical devices, then as collaborative devices, and, finally, as circulating devices. In the third section of the paper, I reflect on the main insights raised in the eight Diagrammatic Manifestos produced through this research. I conclude by discussing how such methods can contribute to more inclusive research on fashion and gender.

\section{SITUATING GENDER FLUID PRACTICES IN THE FASHION INDUSTRY}

Over the last decade, there have been numerous projects taking a gender fluid approach to fashion in Western culture. From small-scale retailers to large fast-fashion brands, there are a few prominent European events worth mentioning: Rad Hourani's presentation of the first unisex haute couture collection at Paris Fashion Week in 2013, the collaboration of London-based unisex label Toogood with the department store Selfridges on a temporary "Agender" retail space in 2015, and the collection "Ungendered" launched by fast-fashion brand Zara in 2016. The unisex clothing brand Lane FortyFive and the gender fluid fashion retailer Verv London, whose founders participated in this research, were established in 2016 and 2017 respectively. Such brands and retailers produce a large number of images to promote each of their new collections or seasons through campaigns, look books, and editorials in fashion magazines. These images help in conveying to consumers that their products can be purchased and worn regardless of gender identity, which contrasts with how the clothing industry usually functions. Indeed, when fashion brands sell clothing exclusively as womenswear and menswear, they expect consumers to express themselves through these two distinctive categories and the ideals of femininities and masculinities that constitute them. This divided market orients bodies towards two dominantly validated modes of identification - as women through womenswear or as men through menswear - and thus simultaneously invalidates others. This legiti- 
mize, marginalize, and stigmatize certain gender practices over others (Barry, 2017; Budgeon, 2013). Such hierarchies are maintained through regulatory processes of repetition (Butler, 1990) that can be identified in how the fashion industry divides its fashion weeks, retail spaces, and magazines according to the gender binary. Fashion photography is instrumental to the preservation of these market categories because it is one of the mediums through which the fashion system and its discourse are produced (Aspers and Godart, 2013; Barthes, 1967; Jobling, 1999; Moeran, 2006).

It is important to take into consideration the commercial end and multiple stakeholders involved in the production of fashion imagery. Fashion photography results from a continuous process of negotiations between the main actors of its field: photographers, brands and their press offices, model agencies, and magazines (Aspers, 2001). This network facilitates the production of fashion imagery, but also conditions it (Aspers, 2001; Lynge-Jorlén, 2012; Moeran, 2006; Titton, 2016). For instance, a participant of the research told me about a discord with a model agency; the agency had prevented them from using a particular photograph publicly in which one of their male models is featured wearing high heels. The agency seemed to be concerned that the photograph could reduce chances for the model to be booked by major brands because it associated him with queer, homosexual, transsexual, or non-binary identities. Not only does this example evince homophobia and transphobia, it also demonstrates how organizations such as model agencies can restrict the representation of identities that are different from the dominant heteronormative discourse in the fashion industry.

\section{Despite the restrictions they face, the cultural producers I interviewed persist in practicing a gender fluid approach to fashion.}

Drawing on Titton's (2016) argument, I view their practices as "instruments of critique" that challenge the heteronormative, white, Western narrative in mainstream media.

In her study of women's interpretations of mainstream fashion magazines, Crane (1999) demonstrated that readers don't necessarily view dominant gender identities as natural and incontestable. Her study exposes that there is a multiplicity of ways individuals relate to the same representation of gender. I therefore identify the fluidity of gender with this multiplicity of possible relations that individuals make between themselves and normative ideals of masculinities, femininities, or their marginalized alternatives. My argument follows Colebrook, whose Deleuzian perspective considers gender as an "emergence of relations" within a constituted system (2004, p. 286). Accordingly, I understand that gender "occurs through the way these relations are made systematically binary" (Misslin, 2020, p. 5). This implies, then, that the system can be made otherwise. The gender fluid practices I study question how the market of womenswear and menswear systemizes the consumers' relations to their own identities. They produce images that offer different envisioning of what bodies can become within a media landscape dominated by binary understandings of gender. 


\section{THE METHODOLOGY OF THE DIAGRAMMATIC MANIFESTOS}

I designed the method of the Diagrammatic Manifestos to study accounts on the fuidity of gender in fashion photography - as opposed to the polarity of gender. With this project, I wanted to stress that social research and fashion studies must consider appropriate research methods in order to include more diverse experiences of gender to our descriptions of social realities. To do so, I considered Back's (2012) argument on the political implications of methods and responded to Law, Ruppert, and Savage's (2011) call for examining the possible side effects of research methods. In the context of my research, the possible side effects concern the risk of overlooking certain experiences of gender if their ambivalence remain unintelligible to binary understandings of gender.

\section{Since the practices of} fashion photography I study intend to resist the binary systemization of gender, the design of my research method aimed to offer opportunities for describing gender beyond the feminine / masculine polarity.
This methodological issue thus raised the importance of how the researcher's own relation to gender affects the interpretation of the data being enunciated (Adkins, 2002). My intention to research this subject stems from the fact that I think of my own gender identity as fluid and rarely identify with the representations of gender in fashion media. This project has encouraged me to challenge my own way of describing gender. For this reason, I propose a method that facilitates a reflective and collaborative exchange between the fields of sociology and of fashion photography to register diverse ways of describing gender fluidity, formulate the political motivations of gender fluid fashion photography, and identify the limitations and potentials of gender fluid image-making within the fashion industry.

Since I am addressing gender as an emergence of relations systemized into a dominant discourse, I use diagrams to explore how relations can be described differently to preconceived ideas on gender. My method draws on Zdebik's understanding of the Deleuzian diagram (2012). I employed diagrams as research devices for their ability to draw the incorporeal and fluid relations made within static structures (Zdebik, 2012). In this way, the diagrammatic and collaborative data analysis can focus on how the participants' descriptions differ from a binary understanding of gender, rather than how they conform with it. My methodological approach draws on the perspectives of live (Back and Puwar, 2012) and inventive (Lury and Wakeford, 2012) methods that encourage researchers 
to develop innovative devices engaging the multi-modal and sensorial registers through which participants may recall and describe their own lived experiences (Back and Puwar, 2012). I noticed a comparable methodological interest in fashion studies that probe the embodied experiences of fashion (Granata, 2012; Jenss, 2016; Barry, 2017), and there are some research projects in which I could indeed identify methodologies corresponding to the intentions of live and inventive methods (see Luvaas, 2016; Von Busch, 2016; Woodward, 2008). For the purpose of this paper, I point more specifically to Kaiser and Green (2016), who mixed qualitative and quantitative methods to prompt a diversity of accounts on masculinities and fashion consumption, as well as Barry (2017) who employed arts-informed methods to organize a fashion show about his research participants' relations to masculinities. These projects both contribute to demonstrating the fluidity of gender in the way it exposes the multiplicities of relations that can be made between individuals and dominant ideals of masculinities.

\section{IIA. RESEARCH SAMPLE}

I gathered potential participants by looking at the portfolios that most photographers, stylists, make-up artists, and fashion editors share on the social media platform Instagram (Figure 1). Fashion photography producers use portfolios to show their recent projects to their professional network (Aspers, 2001). I selected portfolios from which I could identify a correlation with my research question: images with overlapping signifiers of masculinity and femininity such as men wearing dresses (Figure 2), a focus on photographing subjects of the LGBTQIA $+{ }^{1}$ communities who often challenge heteronormative ideals (Figure 3), hashtags relating to gender fluidity (Figure 4), or, more evidently, the explicit labelling of their work (Figure 5). I contacted photographers, magazine editors, or directors of brands by email with a description of my research and its objectives. Those that did respond to my request had certainly recognized their own practice and interests in my research questions, hence legitimizing their involvement as participants in this research.

I conducted interviews with a total of eight participants. I met with four photographers, a fashion editor for a small-scale fashion magazine, a photographic editor for a larger scale fashion and beauty magazine, the founder and designer of a unisex clothing brand, and the director of a gender fluid fashion brands' retailer. The sample is very diverse, hence representative of the heterogeneous international fashion scene in London. The participants have a variety of educational and professional backgrounds (fashion, banking, law, sociology), ethnicities (South-Asian, Black, White), nationalities (British, American, Singaporean, Indian, Italian, German), sexual orientations (homosexual, heterosexual), and gendered identities (non-binary, women, men). They all worked in the fashion industry for around ten years or less. 

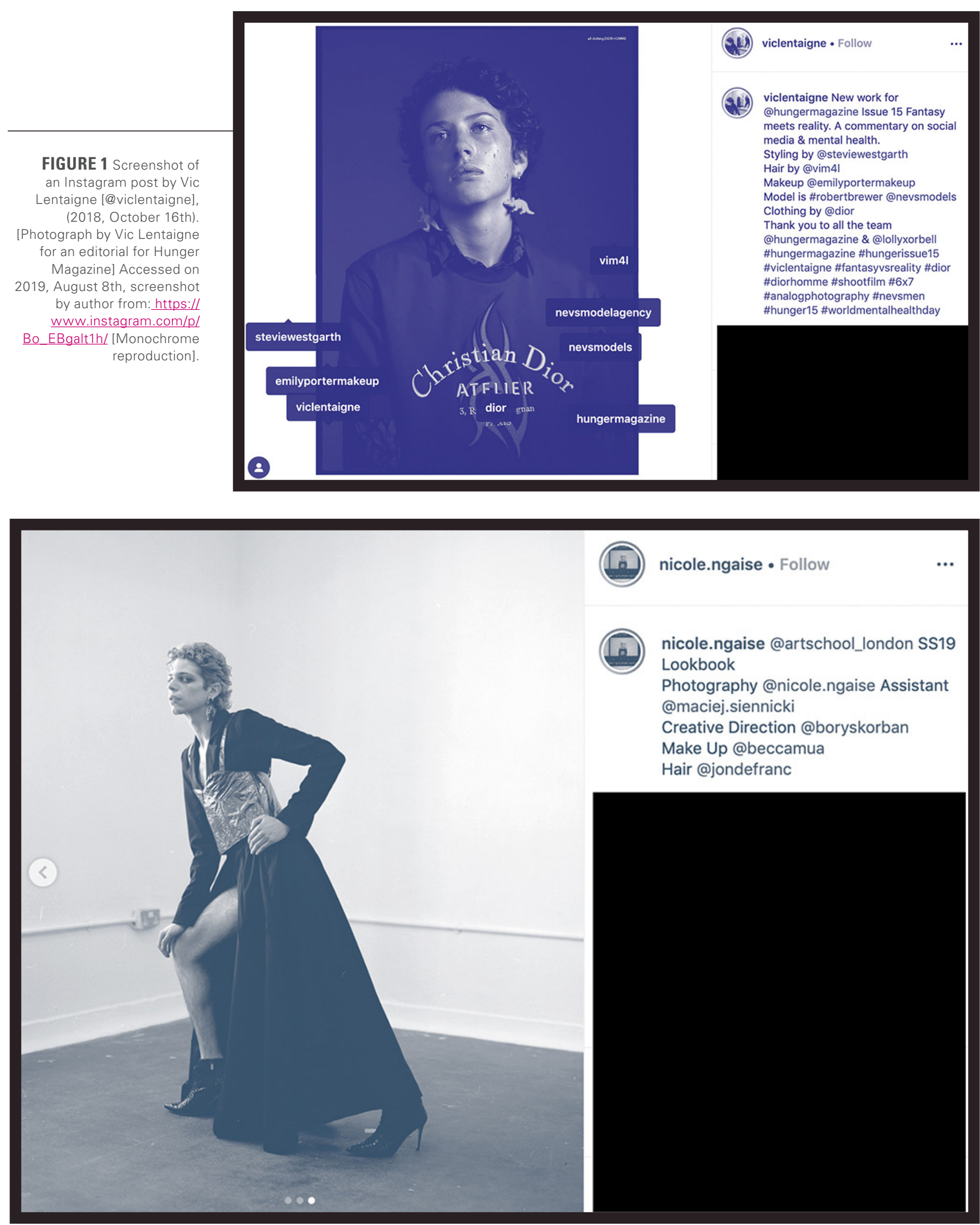

FIGURE 2 Screenshot of an Instagram post by Nicole Ngai [@nicole.ngaise], (2018, September 12th). [Photograph by Nicole Ngai for Art School London's look book Spring Summer 2019] Accessed on 2019, August 8th, screenshot by author, from: https://www. instagram.com/p/Bnnw0ofFisM/ [Monochrome reproduction]. 
Direction and Photography by me, styling @prinxlydia, make up/hair @ksavijoshi, photo assistance

@re_shehata \#queergaze \#analogue \#photography \#mamiya645 \#lgbtqia \#queer \#editorial \#oneofthem \#transgaze \#nonbinary \#love \#couple \#fashion \#kiss \#soulmate \#instalove

\section{verv.Iondon.}

\#danshan \#genderninconforming \#breakthebinary \#queer \#queerbusiness \#lgbtq \#gay \#queerfashion \#degenderfashion \#agender \#gnc

\#genderlessfashion \#unisex \#unisexfashion \#genderfluid \#nonbinary \#beauty \#pride \#gaypride \#fashion \#style \#shop \#sale
FIGURE 4 Screenshot of the hashtags used by @ verv.london in a comment for their Instagram post by Verv London [@verv. Iondon], (2020, August 12th). Accessed on 2020, August 20th, screenshot by author, from: https://www.instagram. com/p/CDylhdjAFsj/ [Monochrome reproduction].
FIGURE 3 Screenshot of an Instagram post by Henri T Art [@henri_t_art], (2019, April 18th). [Photograph by Henri T Art] Accessed on 2019, August 8th, screenshot by author, from: https://www. instagram.com/p/BwaEesHgzw3/ [Monochrome reproduction]. 


\section{Unisex, hand-made clothing label based in London.}

Our designs draw influence from a mix of traditions, timelines, geographies, people both real and fictitious, human behaviors, habits, and stories. Relationship between the garment and the wearer is an endangered concept in this time and age of mass production and fickle nature of fashion and trends. The importance of this

FIGURE 5 Screenshot of the website of Lane FortyFive. Accessed on 2019, August 8 th, screenshot by author, from: https://lanefortyfive. com/ [Monochrome reproduction].

\section{IIB. A BRIEF DESCRIPTION OF THE DIAGRAMMING PROCESS}

Each step of the diagramming process is illustrated with the diagrams made with the interviews with photographer $\mathrm{Ni}^{-}$ cole Ngai. I elaborate further on the method in the upcoming subsections.

This empirical research ideally consisted of a minimum of two interviews with each participant. Over a period of three months, I managed to do three interviews with one of the participants, two interviews with five of them, and only one interview with two of them. The semi-structured interviews lasted around forty-five minutes and were audio-recorded. In the first interview, I asked participants to describe their usual working process from the commission to the publication of the photographs. Simultaneously, I sketched diagrams to visualize their descriptions (Figure 6). After this first interview, I directly transcribed our conversation into a diagrammatic form. This consisted of organizing quotes and keywords from the transcripts into a graphic system that was helping me to analyze their descriptions and formulate questions for the second interview. The evolution of the transcript through diagrams can be tracked from Figure 7 to 10 . 
In the second interview, I presented my interpretation of our first interview by showing the diagram to the participant. During this discussion, I took notes directly onto the printed diagram (Figure 11). Before the interview, I asked participants to come with mood boards that they had previously worked on. I used both the diagram and their mood boards to elicit their visual references, aesthetic influences, and how these connect with their relation to gender. Then, I began transcribing the second interview directly onto the diagram (Figure 12). This second phase of diagramming helped to complement and question my first interpretations. I inserted new keywords in the diagrams, erased parts that no longer seemed relevant, or expanded the ones that now seemed more important (in the context of a third interview, the two last phases were repeated; although not involving the mood boards but simply discussing the diagram more thoroughly).

After conducting all of the interviews, I briefly stopped the process of diagramming to summarize my interpretation of the interviews into a single narrative of about 180 words (Figure 13). The text was later put back into diagrammatic forms (Figure 14 and 15). If I only managed to conduct one interview with a participant, the text was completed directly after the first phase of diagramming. I then asked each participant by email to review the text and send me a photograph from their portfolio that they would like to incorporate into the manifesto (Figure 16). I did not ask images from the participants that wished to remain anonymous. After receiving all participants' final consent and their preferences regarding anonymity, I finalized the visual designs of the Diagrammatic Manifestos before launching their public circulation (Figure 17). 


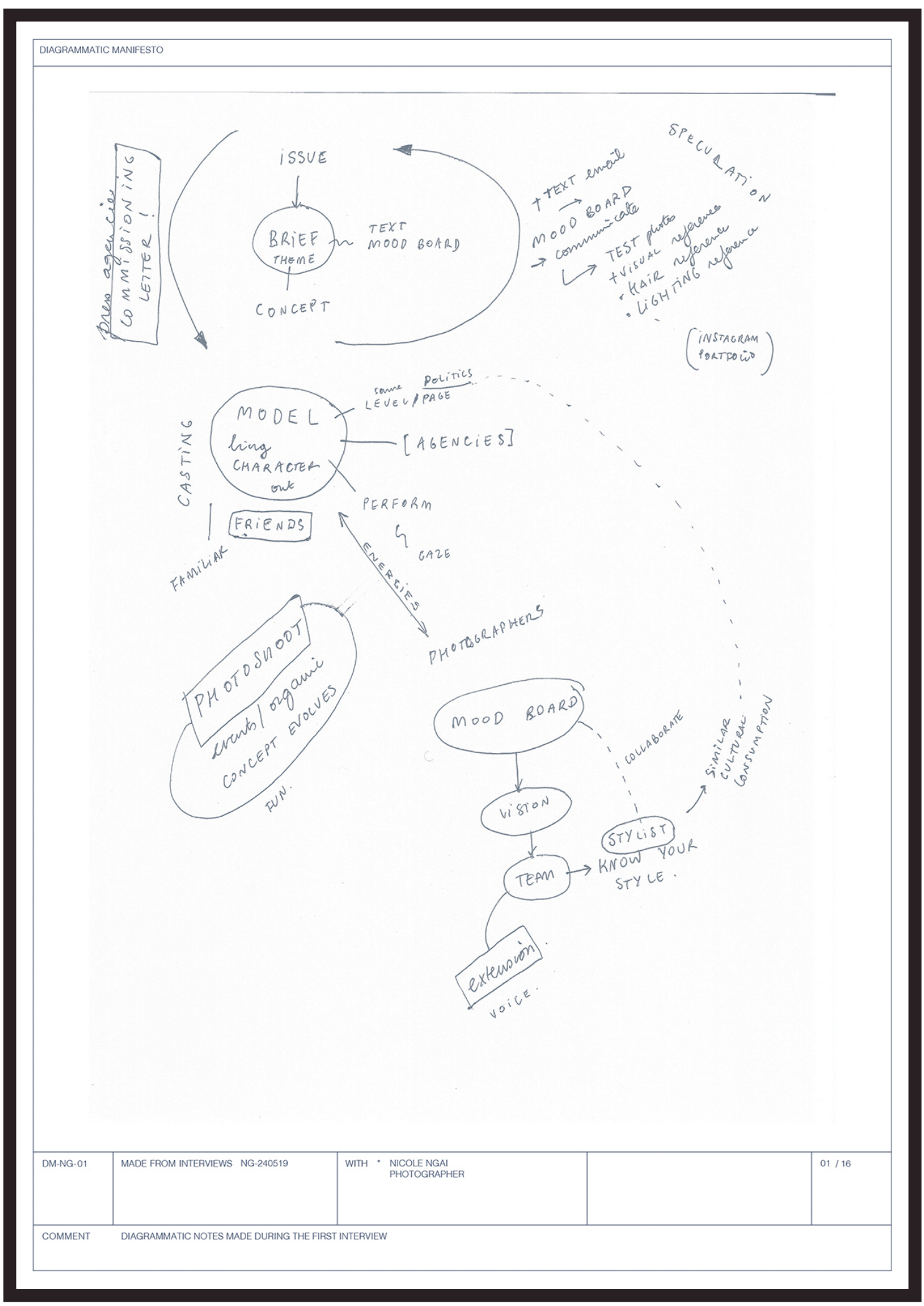

FIGURE 6 Notes taken during the first interview with Nicole Ngai. 


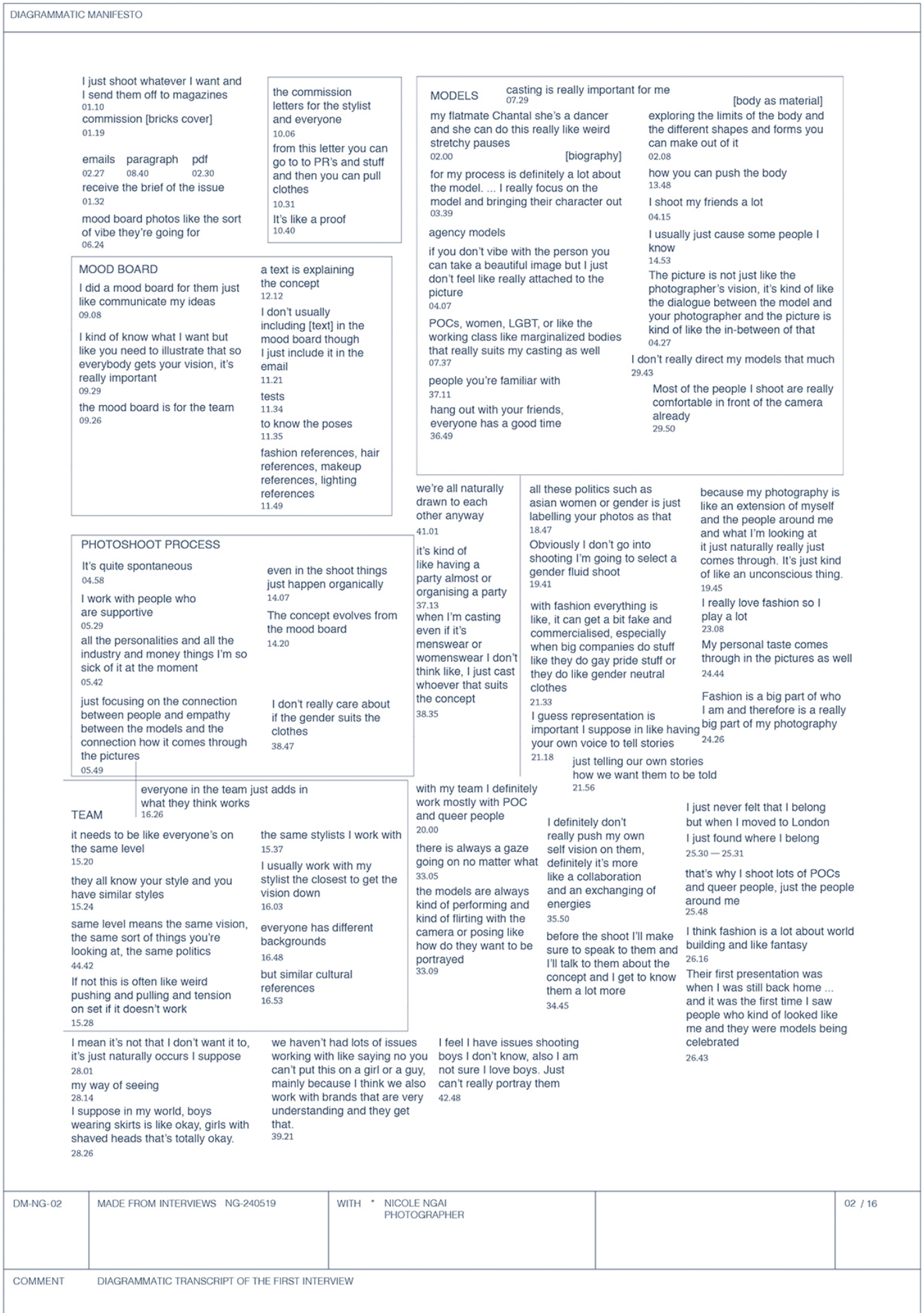

FIGURE 7 Diagrammatic transcript of the first interview. 


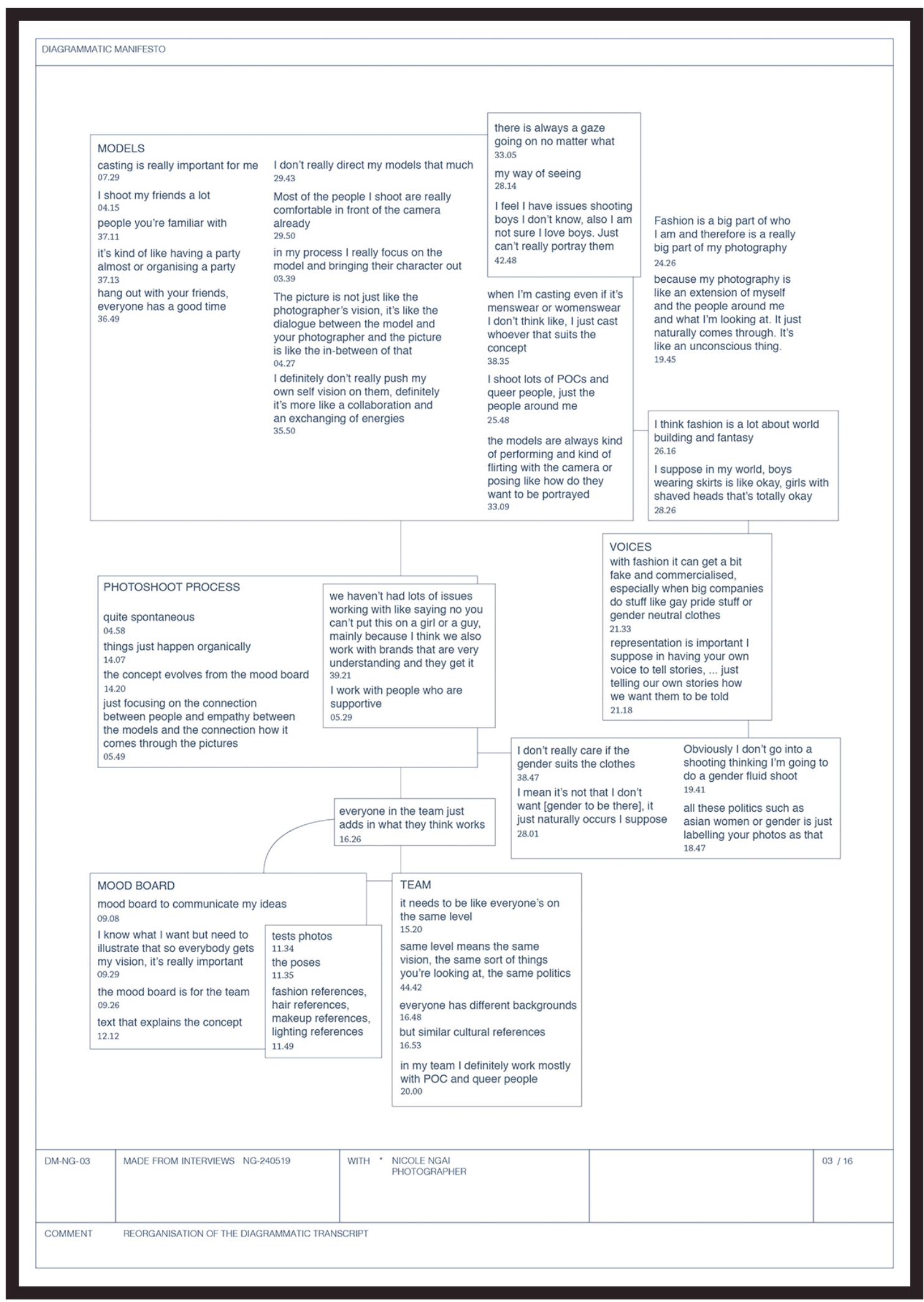

FIGURE 8 First reorganization of the diagrammatic transcript. 


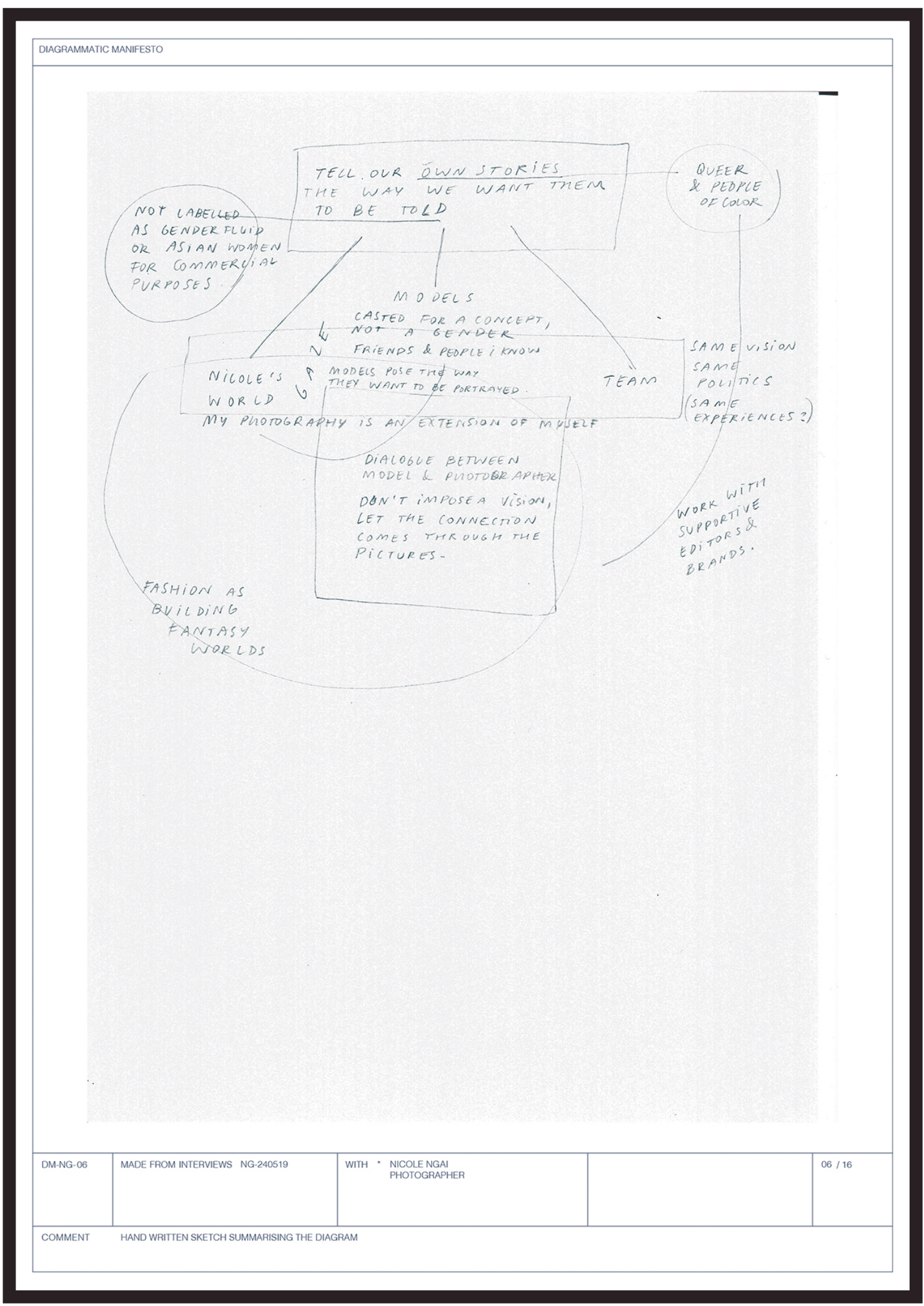

FIGURE 9 Hand-sketched diagram 


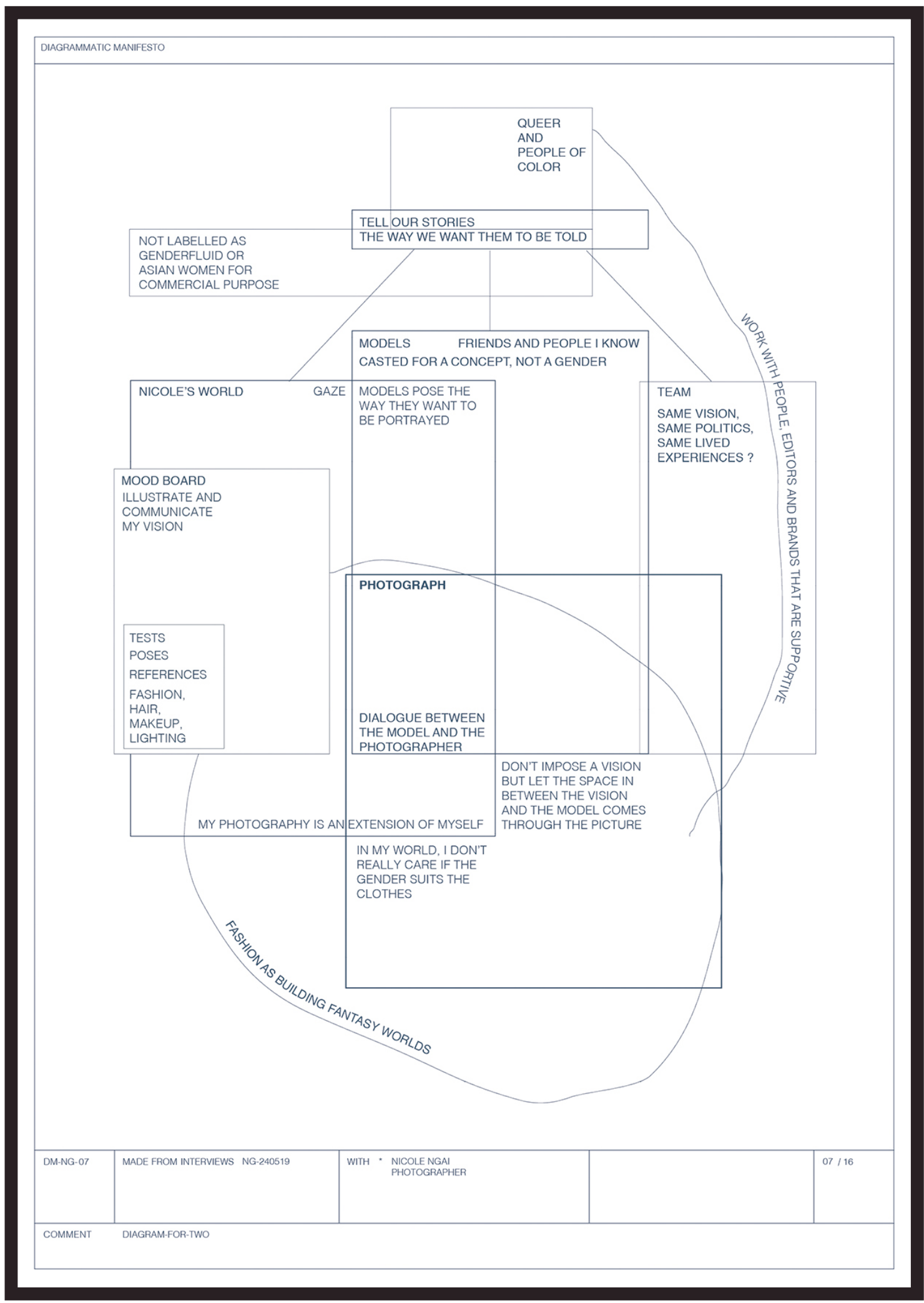

FIGURE 10 The diagram presented to Nicole Ngai for our second interview. 


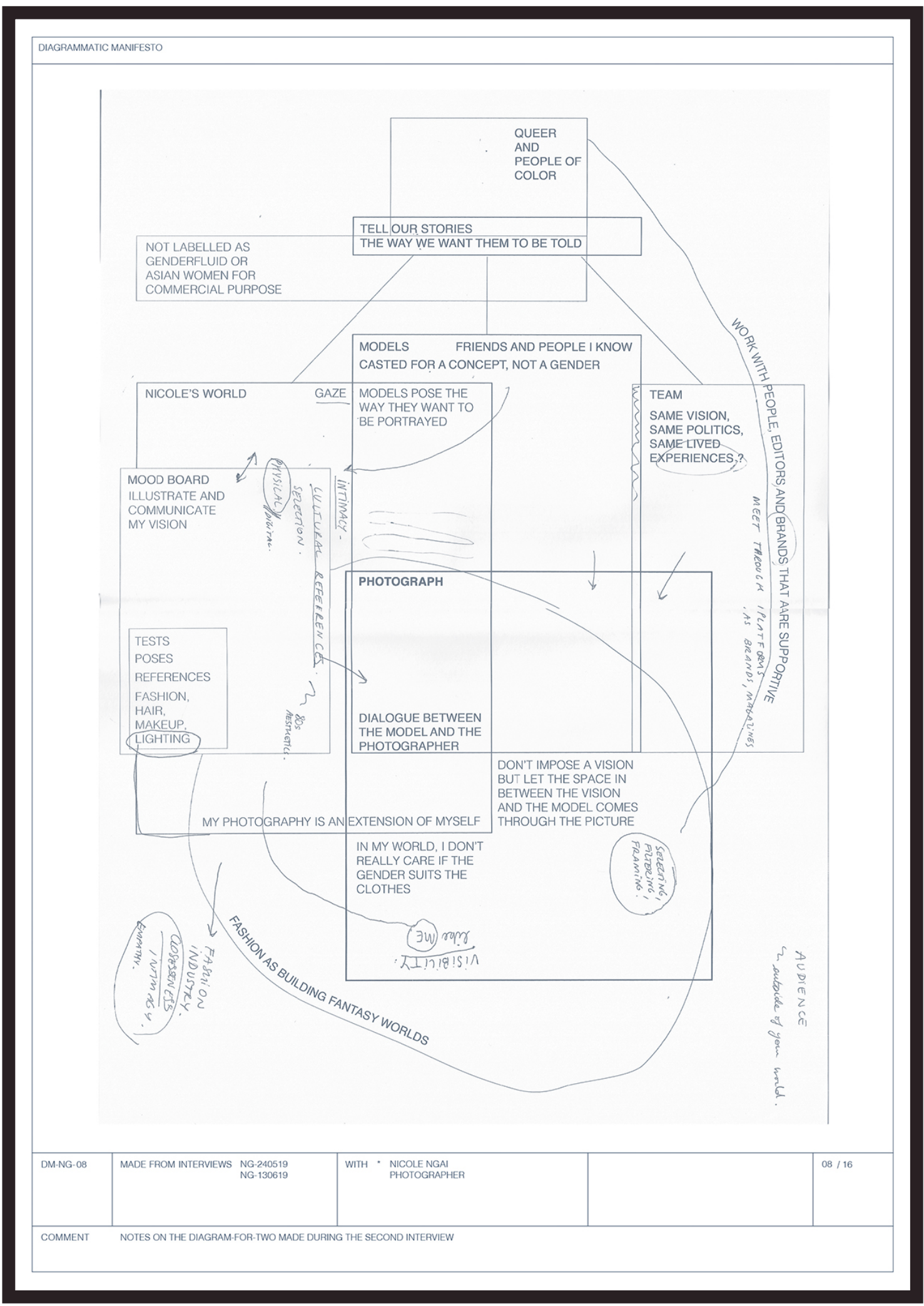

FIGURE 11 Hand-written annotations of the diagrams made during the second interview. 


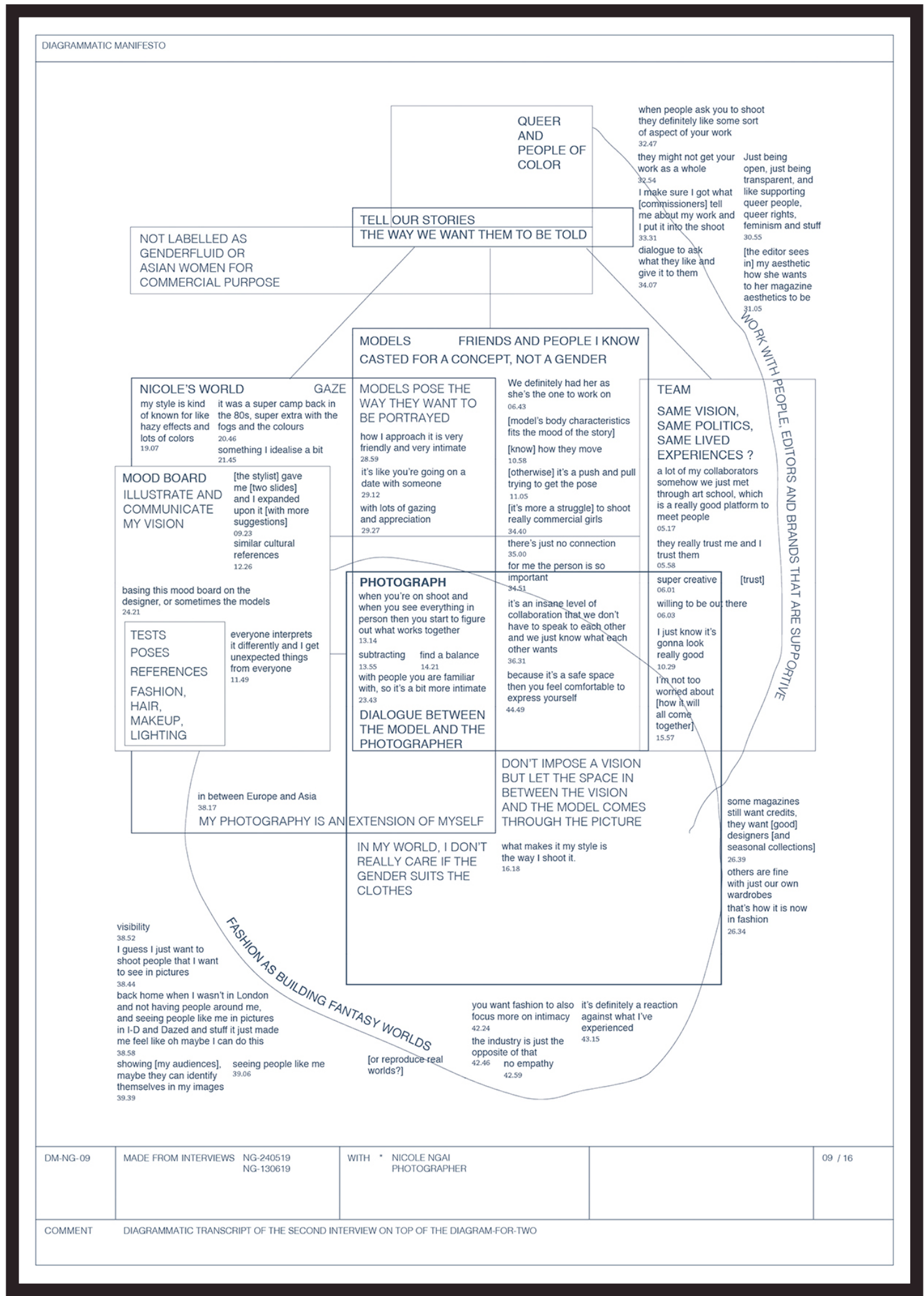




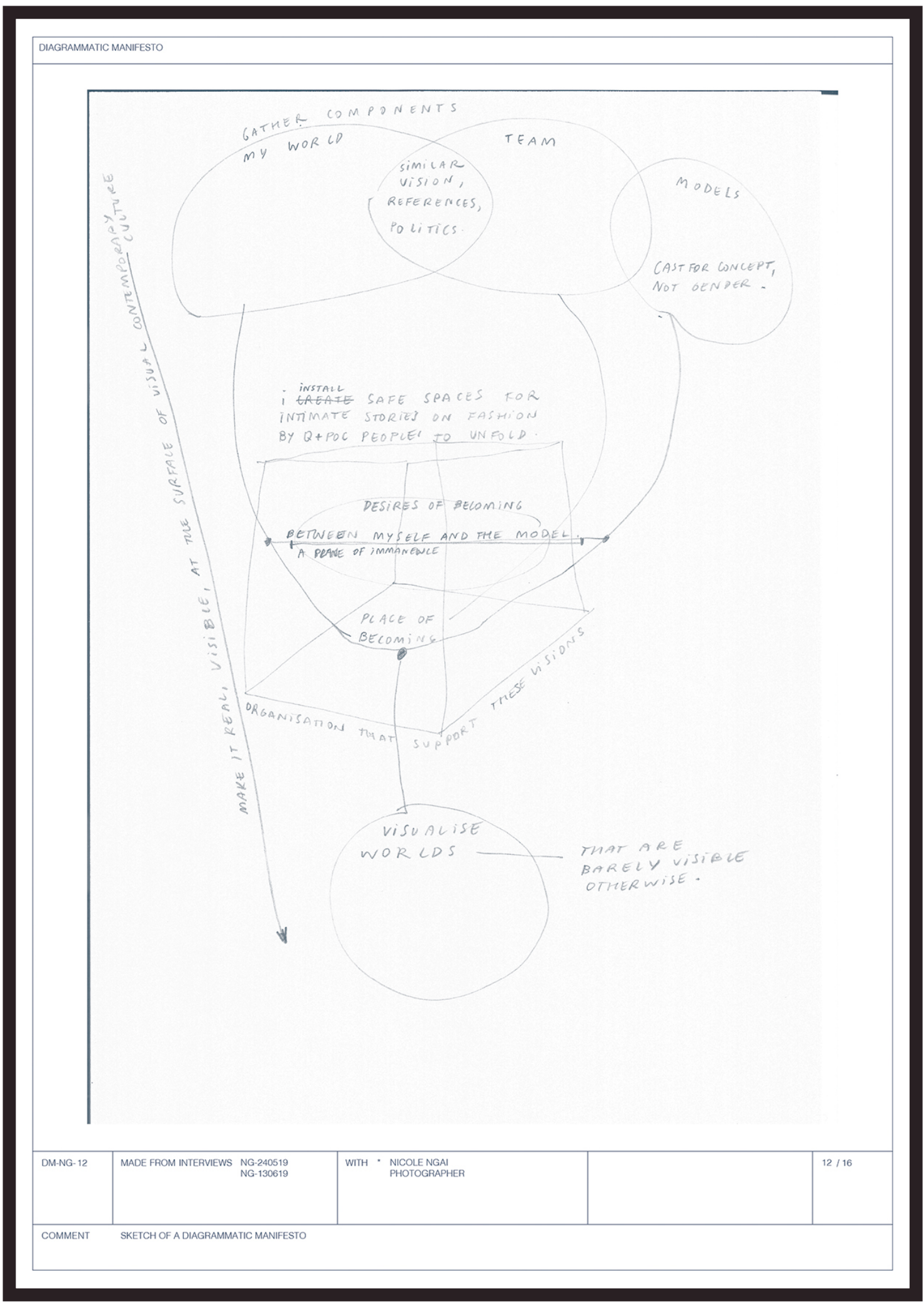

FIGURE 14 Sketch of a final diagram for a manifesto. 


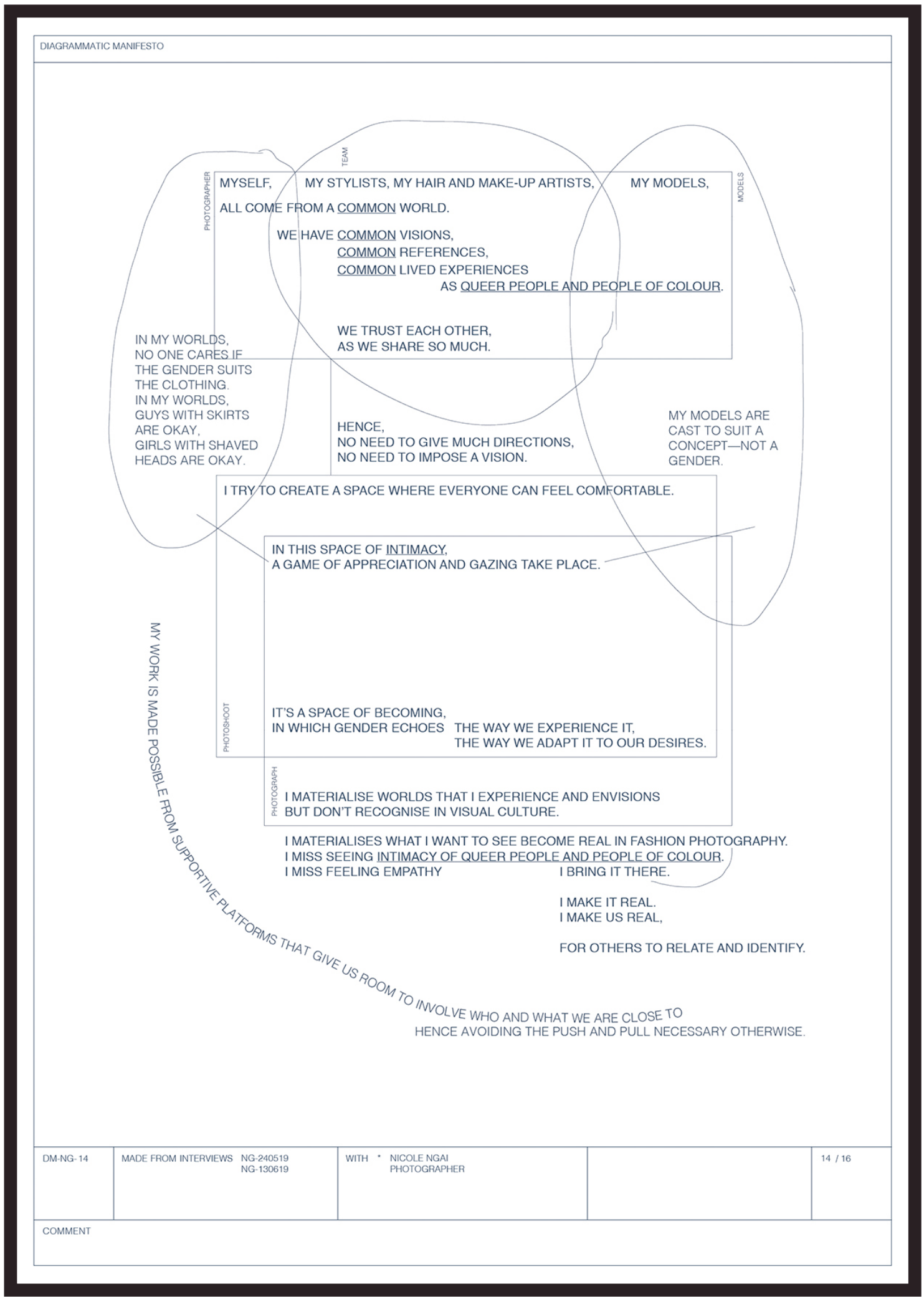

FIGURE 15 Evolution of the text within a new diagram form for the manifesto 


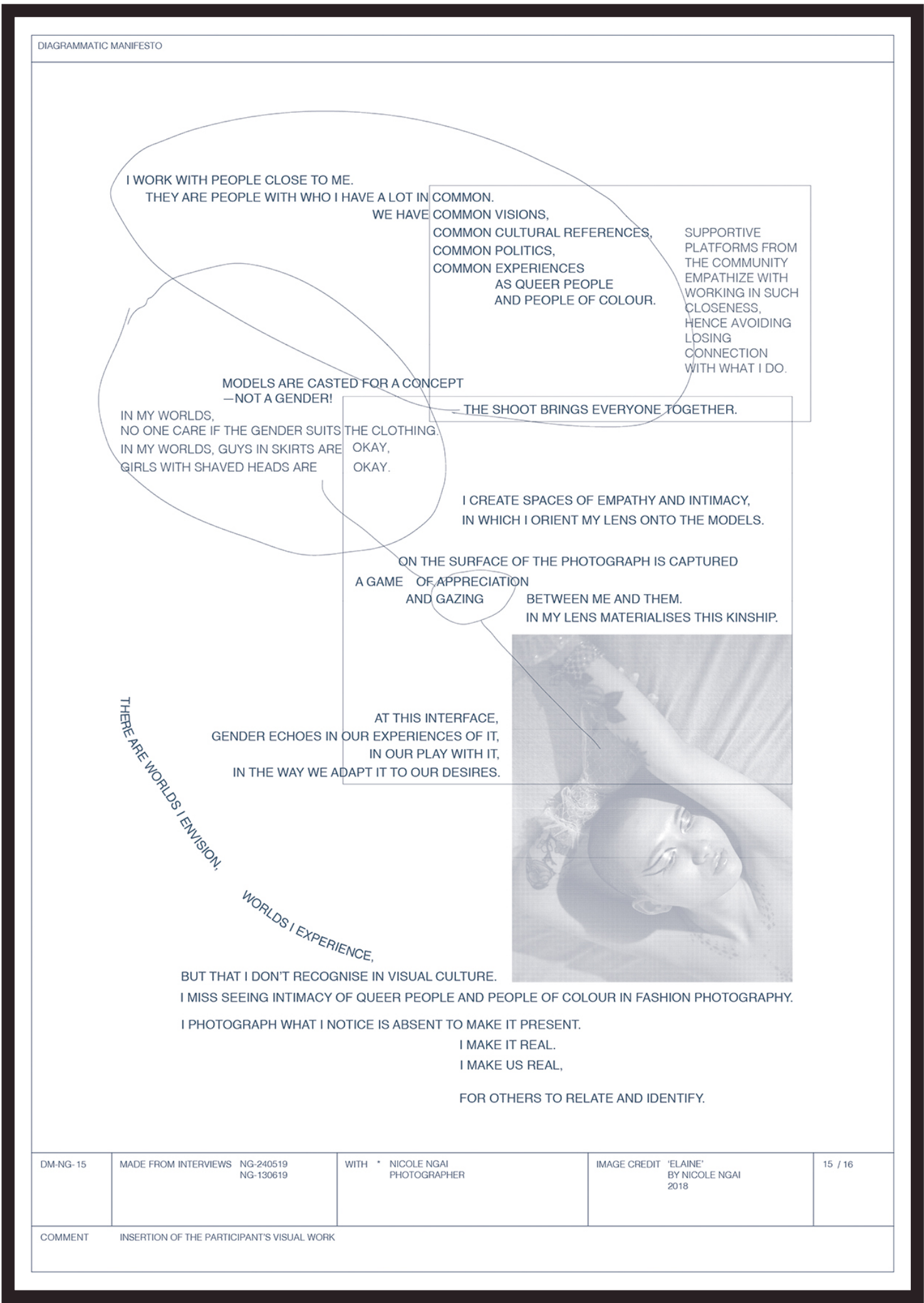

FIGURE 16 Insertion of the photograph shared by Nicole Ngai in the diagram. 
I WORK WITH PEOPLE WHO ARE CLOSE TO ME.

SUPPORTIVE

PLATFORMS FROM

THE COMMUNITY

EMPATHIZE WITH

WORKING IN SUCH

CLOSENESS,

HENCE AVOIDING

LOSING

CONNECTION

MODELS ARE CAST COMMON POLITICS,

AS QUEFR PEOPLE WITHWHATTO AND PEOPLE OF COLOUR.

IN MY WORLDS,

NO ONE CARE IF

IN MY WORLDS, GUYS IN SKIRTS ARE OKAY,

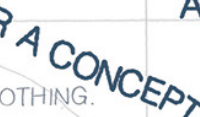

NOT A GENDER!
THE SHOOT BRINGS EVERYONE TOGETHER.

I CREATE SPACES OF EMPATHY AND INTIMACY, IN WHICH I ORIENT MY LENS ONTO THE MODELS. ON THE SURFACE OF THE PHOTOGRAPH IS

A GAME OF APPRECIATION CAPTURED
AND GAZING
BETWEENME
AND THEM.
IN MY LENS MATERIALISES THIS KINSHIP.

$\lambda$ ON THE INTERFACE,

YARE

GENDER ECHOES IN OUR EXPERIENCES OF IT, ARE

IN OUR PLAY WITH IT,

IN THE WAY WE ADAPT IT TO OUR DESIRES.

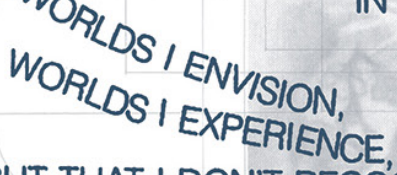

BUT THAT I DON'T RECOGNISE IN VISUAL CULTURE.

I MISS SEEING INTIMACY

OF QUEER PEOPLE

AND PEOPLE OF COLOUR

IN FASHION PHOTOGRAPHY

I PHOTOGRAPH WHAT I NOTICE IS

ABSENT

O MAKE IT PRESENT.

I MAKE IT REAL

I MAKE US REAL. 
IIC. DIAGRAMS AS

ANALYTICAL DEVICES

Instead of transcribing the interviews by following the chronological order of the audio recording, I directly arranged my transcripts graphically (Figure 7). I grouped quotes thematically and drew lines to visually map the relations between these groups (Figure 8). I made most of the diagrams with graphic design software on my computer, but sometimes sketched a few by hand to visualize more abstract structures (Figure 6,9 , and 14). In this method, I did not simply insert every transcript into the template of a diagram but rather organized different diagrams according to the narrative of each participant.

\section{The diagrammatic method hence visually emphasized the different ways they had talked about their lived experiences: for instance, one participant focused on their collaborations with stylists, whereas another elaborated on their negotiations with model agencies.}

This helped me to clarify my own understanding of their narratives and adjust the diagrams accordingly. Thinking of the method as inventive (Lury and Wakeford, 2012), I used the diagrams as open-ended devices that evolve responsively to the participants' insights. The logic of their reorganization arose out of each participant's way of describing their practices of fashion photography, thus allowing the data to generate its own form (see Lury and Wakeford, 2012). 
The method follows an ontology of differences rather than a logic of identity (Linstead and Pullen, 2006) in the way that it resists the temptation of clearing out the complexities of the relations between bodies, dress, and gender. In fact, it rather expands and diffracts them. The more traditional methods of systemizing, coding, and framing similarities between participants may reduce their individual experiences of gender only to what they have in common (see James, 2013; MacLure, 2013).

Through the diagrams, I "filter[ed] out excessive elements" from the transcripts and "translate[d] the essential elements" into a visual map (Zdebik, 2012, p. 66). This consisted of translating the long stories or parts that were less concerned with my research questions into clearer and shorter texts that became manifestos (Figure 10). Through this process, I produced a large number of diagrams. Each stand as a passage from one to another, marking the steps I have taken to interpret the qualitative data. They form an archive that can be used to trace back my analytical translation and locate the anecdotes evoked in the final text of the manifesto (Figure 18, 19, and 20 in comparison to Figure 21, 22, and 23). The texts were written in first person and echoed the participants' verbal formulation. I edited them using my perspective as a researcher to connect their descriptions with sociological terms and theories such as Muñoz's horizons (Figure 35) and illuminations (Figure 34) of queer utopias (2009) or Deleuze and Guattari's multiplicities (Figure 33) in their notion of identity as a never-ending process of becoming (1987). 
FIGURE 18 First extract of the text for Nicole Ngai manifesto.
I INSTALL A SPACE WHERE EVERYONE SHOULD FEEL COMFORTABLE, TO REVEAL THEMSELVES AND SHARE FROM THEMSELVES.

BECAUSE OF THIS INTIMACY,

THERE IS NO NEED FOR ME TO GIVE MUCH DIRECTIONS,

NO NEED TO IMPOSE MY VISION.
FIGURE 19 Second extract of the text for Nicole Ngai manifesto.
BETWEEN MYSELF AND THE MODEL, A RELATION EMERGES, A GAME OF APPRECIATION AND GAZING OF ONE ANOTHER.

FIGURE 20 Third extract

of the text for Nicole Ngai manifesto.

I MAKE US REAL AT THE SURFACE OF VISUAL CULTURE. I HOPE OTHERS CAN RELATE AND IDENTIFY.

\begin{tabular}{|l|}
\hline for me the person is so \\
\hline important \\
34.51 \\
it's an insane level of \\
collaboration that we don't \\
have to speak to each other \\
and we just know what each \\
other wants \\
36.31 \\
because it's a safe space \\
then you feel comfortable to \\
express yourself \\
44.49 \\
with people you are familiar \\
with, so it's a bit more intimate \\
23.43
\end{tabular}

FIGURE 21

Extract of the transcript of the second interview with Nicole Ngai.
I guess I just want to

shoot people that I want

to see in pictures

38.44

back home when I wasn't in London and not having people around me, and seeing people like me in pictures in I-D and Dazed and stuff it just made

me feel like oh maybe I can do this

38.58

showing [my audiences], seeing people like me maybe they can identify $\quad 39.06$

themselves in my images

39.39
FIGURE 22 second extract of the transcript of the second interview with Nicole Ngai. 
IID. DIAGRAMS AS

COLLABORATIVE DEVICES

\section{During the research process, the diagrams were acting as communicative tools between myself and the participants to collaboratively define their approach to fashion photography.}

They were used as visual maps to prompt conversations, discuss the interpretation of their work, propose different formulations, or add missing elements. In this way, I involved the participants in the reorganization of their own descriptions to edit their manifestos. The method facilitated a process through which they could reflect on what motivates their creative work and how to explain or articulate this. While reflecting on the diagram's content, they were pointing at the lines or spaces of the visual map, sometimes assimilating terms I was proposing into the way they then continued to describe their practices. However, I also encountered limitations to the diagrams' collaborative capacities. Whilst I invited the participants to write and draw on the diagram at multiple stages of the research process, only a couple of them did indeed choose to annotate (Figure 24). In order to improve my methodology, I could develop a more accessible and interactive use of the diagrams.

FIGURE 24 Photograph by participant Saorla Houston sent to the author for suggesting modifications to her manifesto. [Monochrome reproduction]

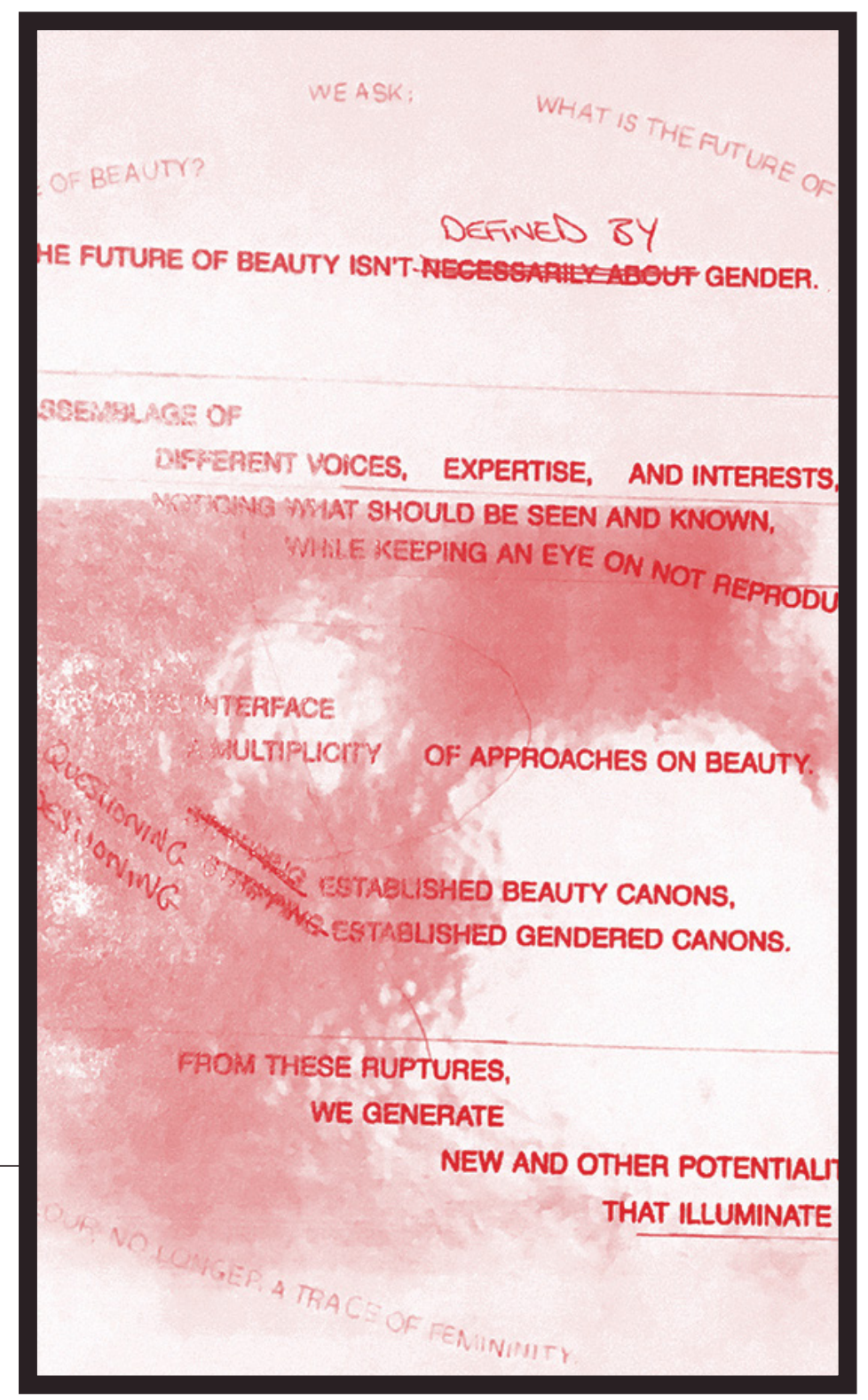


IIE. DIAGRAMMATIC MANIFESTOS AS CIRCULATING DEVICES

The continuous exchange around the diagrams ensured that the participants were confident with how the manifestos represent their perspectives as they circulate publicly. An index at the bottom of the poster shares the details of with whom each manifesto was produced (Figure 25). Six of them were very keen to associate their names with the manifestos. In these instances, we discussed their preferred pronouns, names or nicknames, and professional title. Yet the non-anonymity of participants raised the ethical responsibility of the research to not jeopardize their careers, hence removing a certain level of criticality from the public research outcome. I was careful not to edit the manifesto in a way that confronts the industry too heavily in order to avoid obstructing the relationship between the participants and their professional networks. However, two of the eight manifestos remain anonymous. Interestingly, these are the manifestos of the participants that I interviewed only once. This suggests that a higher level of trust was developed with participants with whom I had multiple conversations. As a result, the anonymous manifestos do not include images and only reflect a single conversation. This highlights a shortcoming of my collaborative method: iIt is mostly successful when participants are available over a longer period and requires a considerable investment of time by each participant.
I designed the Diagrammatic Manifestos so that they could be circulated easily and reach a wide audience. They are intentionally easy to reproduce with only one print color and a format fitting international paper sizes from A5 to A1. When displayed side by side (Figure 26), they represent a multiplicity of voices, each signalled by a different color.

\section{The Diagrammatic Manifestos can cir- culate as pamphlets in retail stores, be hung in workspaces, displayed as posters in galleries, and pub- lished as spreads in magazines.}

Many of the participants have shared their manifestos by posting them on Instagram (Figure 27). At the time of writing, the project has been shown in two exhibitions: Snacks, for which a mural installation presented the diagrams made during the research (Figure 28) and Design for Different Futures for which four of the Diagrammatic Manifestos are currently being displayed alongside giveaway prints of the manifestos (Figure 29). 


$\begin{array}{llll}\text { DIAGRAMMATIC MANIFESTO MADE FROM INTERVIEWS } & \text { NG-240519 } & \text { WITH } & \text { NICOLE NGAI } \\ & & \text { NG-130619 } & \\ & & \\ & & \end{array}$

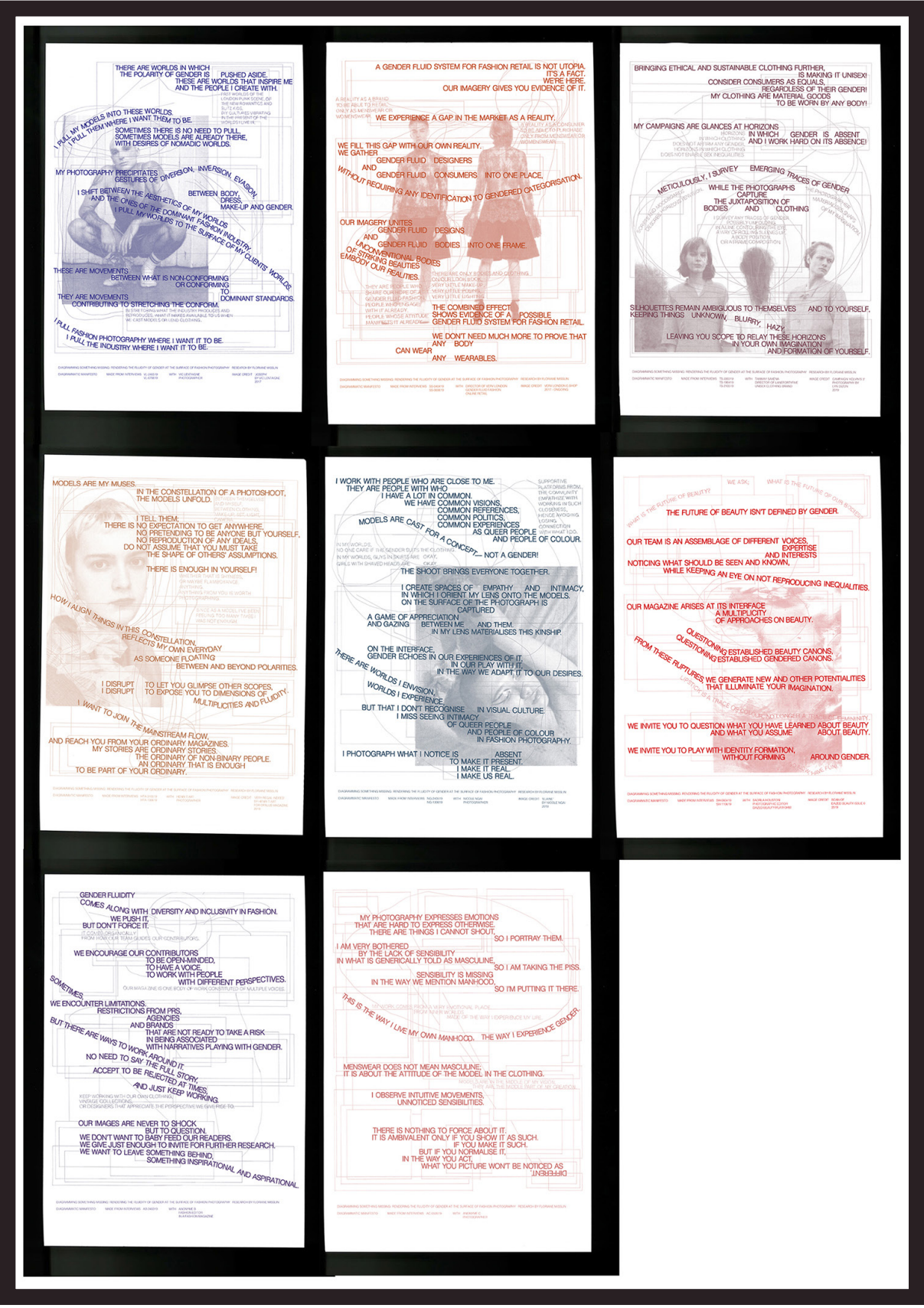

FIGURE 25

The index of

Nicole Ngai's

Diagrammatic

Manifesto.

FIGURE 26 Montage

with the scans of

the Diagrammatic

Manifestos. 

I"ACTUALISE GENDER FLUIDTY BY PULUNG THE AESTHETICS OF THE SUBCULTURAL INTO THE AESTHETICS
OF THE DOMINANT VISUAL CULTURE IN FASHION

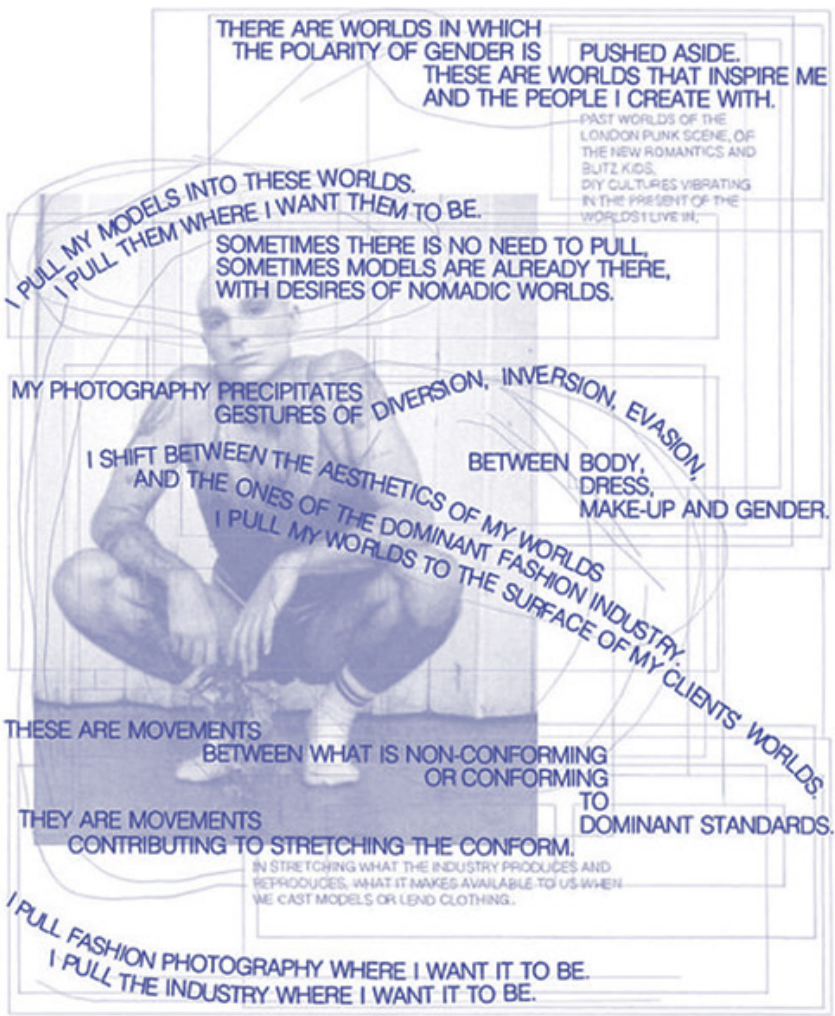

viclentaigne $\cdot$ Following

London, United Kingdom

viclentaigne Thank you @floriane_misslin for interviewing me and making this amazing diagrammic manifesto of my brain and working methods such an amazing project to be involved in! \#photography \#gender \#manifesto \#diagrammicmanifesto \#subculture \#genderbender

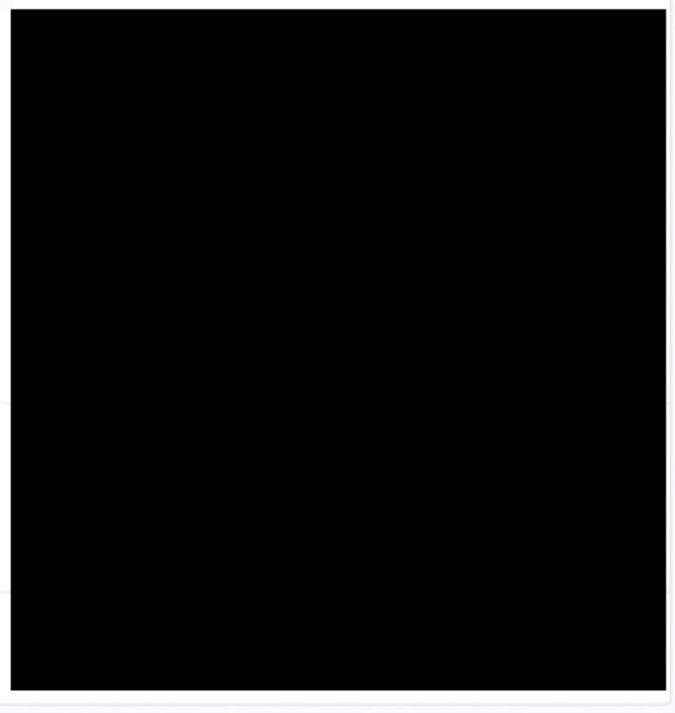

FIGURE 27 Screenshot of an Instagram post by Vic Lentaigne [@viclentaigne], (2019, October 28th). [Digital version of the Diagrammatic Manifesto by Floriane Misslin and Vic Lentaigne] Accessed on 2019, December 15th, screenshot by author from: https://www.instagram.com/p/B4K3YBIA-cV/ [Monochrome reproduction]. 


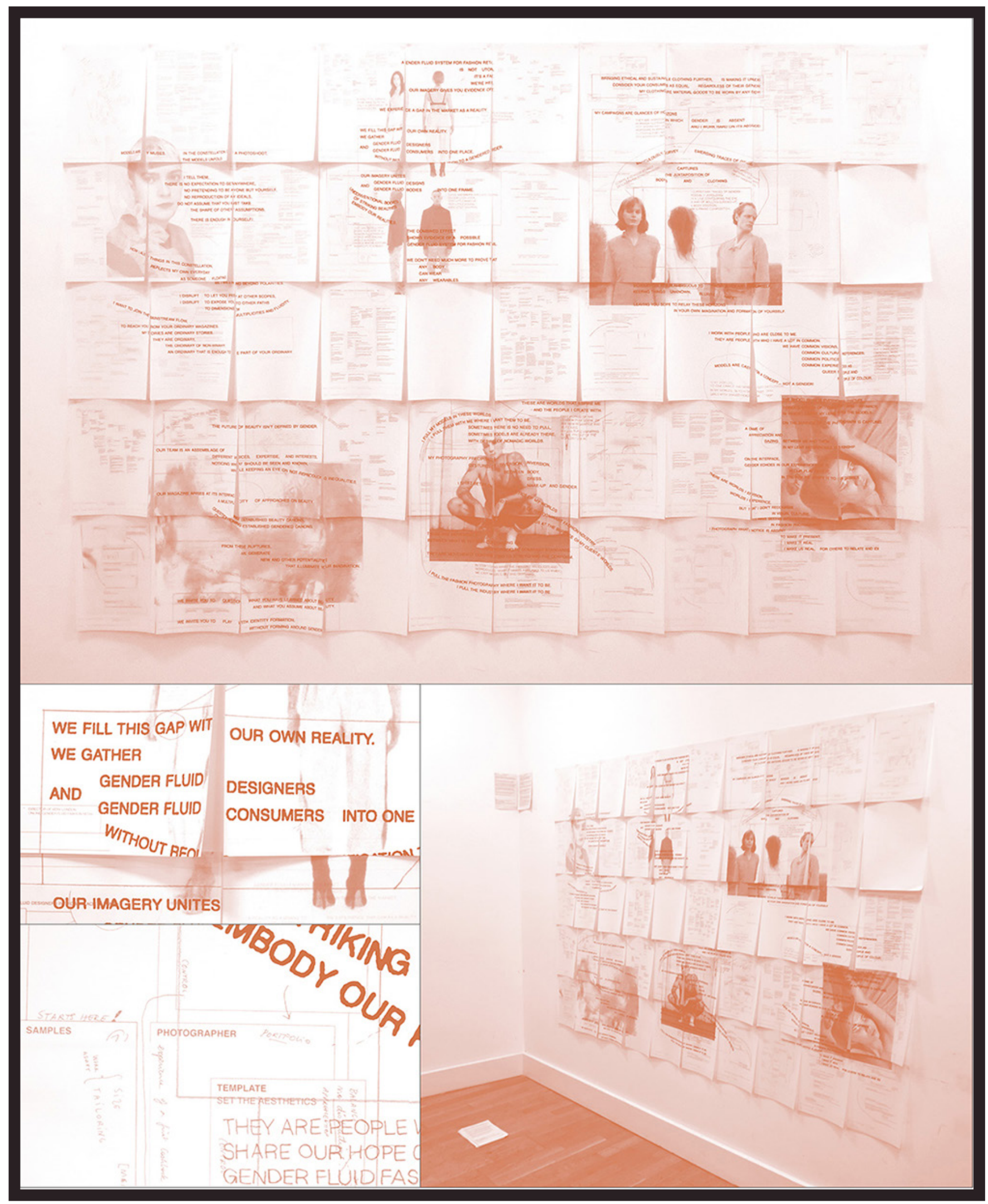

FIGURE 28 Montage of photographs by the author of the installation at the exhibition Snacks on the 26th of July 2019 in Greenwich Community and Arts Centre, London, UK. 


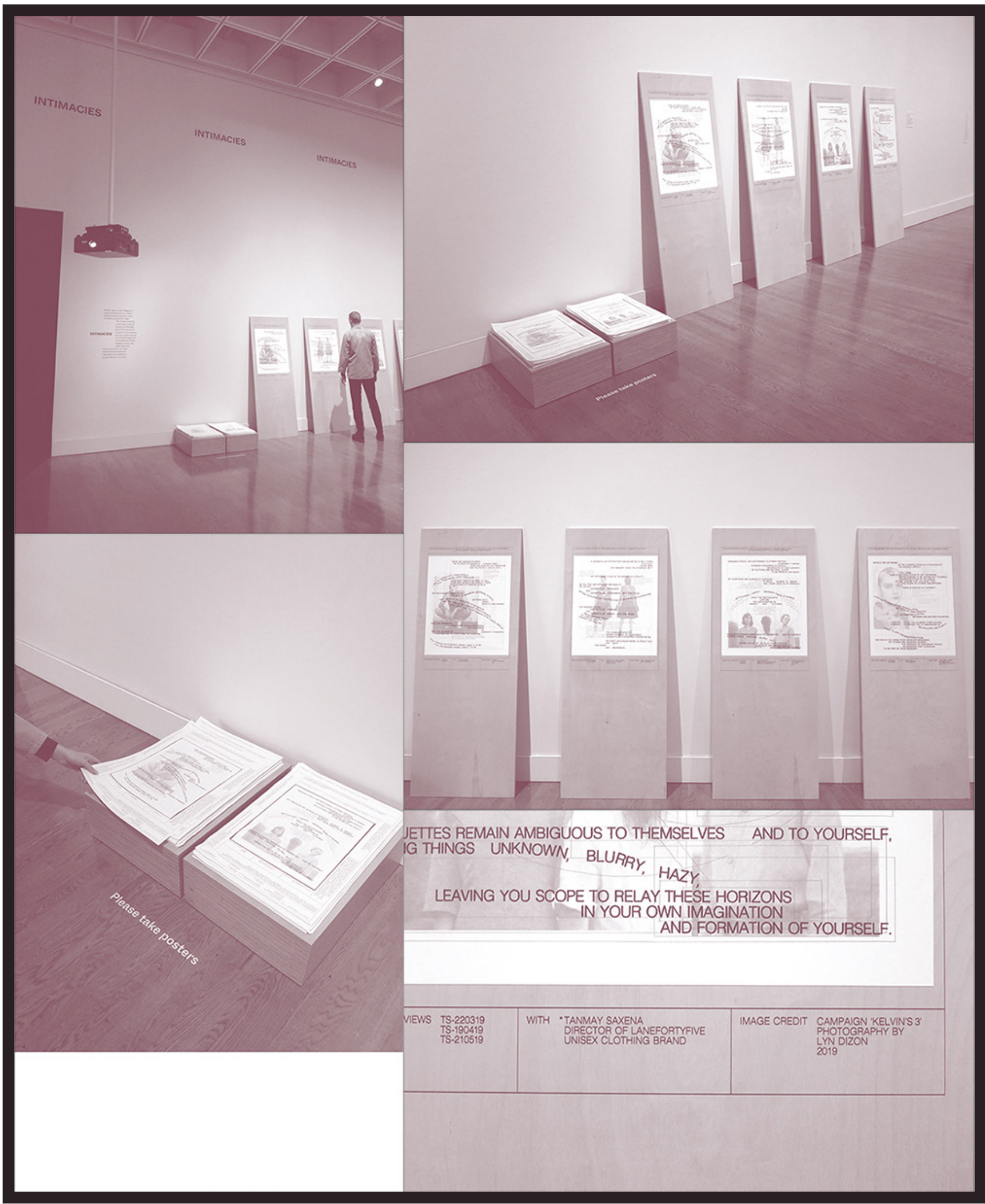

FIGURE 29 Montage of photographs by the author of the installation at the exhibition Designs for Different Futures touring from October 2019 to May 2021 at the Philadelphia Museum of Arts, the Walker Art Center in Minneapolis, and the Institute of Art of 


\section{SOMETHING MISSING IN FASHION PHOTOGRAPHY}

The Diagrammatic Manifestos produced through this research represent eight different ways of defining gender fluid practices of fashion photography.

\section{Together, they describe a collective hope in making the fluidity of gender more visible and integral to fashion media.}

According to Muñoz's view on queer utopias (2009), hope is a mode of critique that insists that things can change and initiates the collective imagination of a different future. Drawing on his perspective, I consider gender fluid practices of fashion photography as acts of "imagining transformation" that manifest a discontentment with the present and challenge its continuity in the future (Muñoz, 2009, p. 9). Muñoz argues that utopias "remind us that there is something missing, that the present and presence (and its opposite number, absence) is not enough" (Muñoz, 2009, p. 100, emphasis is mine). In the manifesto produced with the director of gender fluid fashion retailer Verv London (Figure 30), this something missing refers to the ignored gap between the womenswear and menswear market. As a retailing project, Verv thus intends to fill in this gap with what is missing; the possibility for consumers to purchase clothing without complying to these two normative categories. More generally, participants associated this something missing with the under-representation of certain gender and sexual identities in fashion imagery. This is particularly addressed in the manifestos of three of the photographers; with Andrea $^{2}$ we referred to his practice as a necessity for portraying men in a more sensitive manner (Figure 31), with Nicole Ngai we underlined how her photography represents her queer community of Asian women (Figure 32), and with Henri $\mathrm{T} \mathrm{Art}^{3}$, we discussed the importance for them to photograph a diversity of non-binary identities (Figure 33). The three manifestos demonstrate that gender fluid practices of fashion photography originate from a "shared critical dissatisfaction" (Muñoz, 2009, p.189) of not recognizing their own experiences of gender in fashion imagery, hence producing these missing representations themselves. They utilize fashion photography as a means to bring into being diverse experiences of gender - like their own; a sensitive man, a queer asian woman, a non-binary person - at the surface of commercial images. When they are published on websites, social media, magazines, or billboards, these photographs are being validated and legitimized by multiple stakeholders (see Lynge-Jorlén, 2012; Lynge-Jorlén, 2016; Moeran, 2006; Titton, 2016). They stand as evidence of the possibility to produce and consume fashion beyond the gender binary. Many of the participants discussed their intentions to reach mainstream channels in order to share their experiences of gender with wider audiences. This was most clearly expressed by photographer Henri T Art, who aspires to make non-binary identities more "ordinary" by including their portraits in mainstream fashion magazines. Femininities, masculinities, non-binary, trans, gender fluid, queer, and more, would co-exist onto the same glossy pages. . Inevitably, these diverse portraits 
would convey to magazine readership that bodies can differ from the binary gender ideals of femininity and masculinity, and that these differences are all valid. This ideal can also be seen in the manifesto made with Saorla Houston, photographic editor of the media platform Dazed Beauty. The magazine features a wide range of cosmetic and fashion practices without necessarily associating them with any defined gender identities, thus inviting their readers to explore dress and makeup regardless of gender (Figure 34). It is this diversity that represents the multiplicity of possible relations to gender, hence its fluidity.

Furthermore, nearly all participants mentioned casting their own friends as models, or completing an outfit with their own wardrobe or second-hand clothing for a photoshoot. They do so to avoid the sometimes-difficult negotiations with model agencies and press offices that may simply refuse to associate their models or products with, for instance, an image featuring a male model wearing high heels (see the first section of this paper). This reveals a certain discord between different understandings of gender amongst producers of fashion photography. Tanmay Saxena, founder and art director of the unisex clothing brand Lane FortyFive (Figure 35), described such struggles during a photoshoot for one of his campaigns. The hired photographer was directing male models to pose differently than the female models, reproducing inequalities that the brand actually intends to denounce. Another participant shared a difficult experience while working with a makeup artist who remained confused about using the gender-neutral pronoun "they/them" and gravely offended team members by misusing the pronouns she/her or he/ his. These two anecdotes report actions that reproduce a binary systemization of gender within spaces that intend to resist it. This can affect individuals who experience this binary as a restriction to their self-expression and cause a disruption to their creative work.

\section{In order to minimize the threat of discrimination and stigmatization, these communities create new magazines, brands, and model agencies that grad- ually establish gender flu- id practices as integral to the future of the fashion industry.}

For instance, photographer Vic Lentaigne told me about the model agency Crumb. Founded in London in 2016, Crumb has a category of exclusively gender fluid models and shares guidelines with their clients in regard to pronouns, safety, gender-neutral bathrooms, and fitting rooms. 
A GENDER FLUID SYSTEM FOR FASHION RETAIL IS NOT UTOPIA.

IT'S A FACT.

WE'RE HERE.

OUR IMAGERY GIVES YOU EVIDENCE OF IT.

A REALITY AS A BRAND

TOBE ABLETO RETAIL

ONLY AS MENSWEAR OR

WOMENSWEAR. WE EXPERIENCE A GAP IN THE MARKET AS A REALITY.

WE FILL THIS GAP WITH OUR OWNREALITY.

WE GATHER

GENDER FLUID DESIGNERS

WIT\% AND GENDER FLUID CONSUMERS INTO ONE PLACE,

ONLYFROM MENSWEAR OR NOOAENSWEAR. 


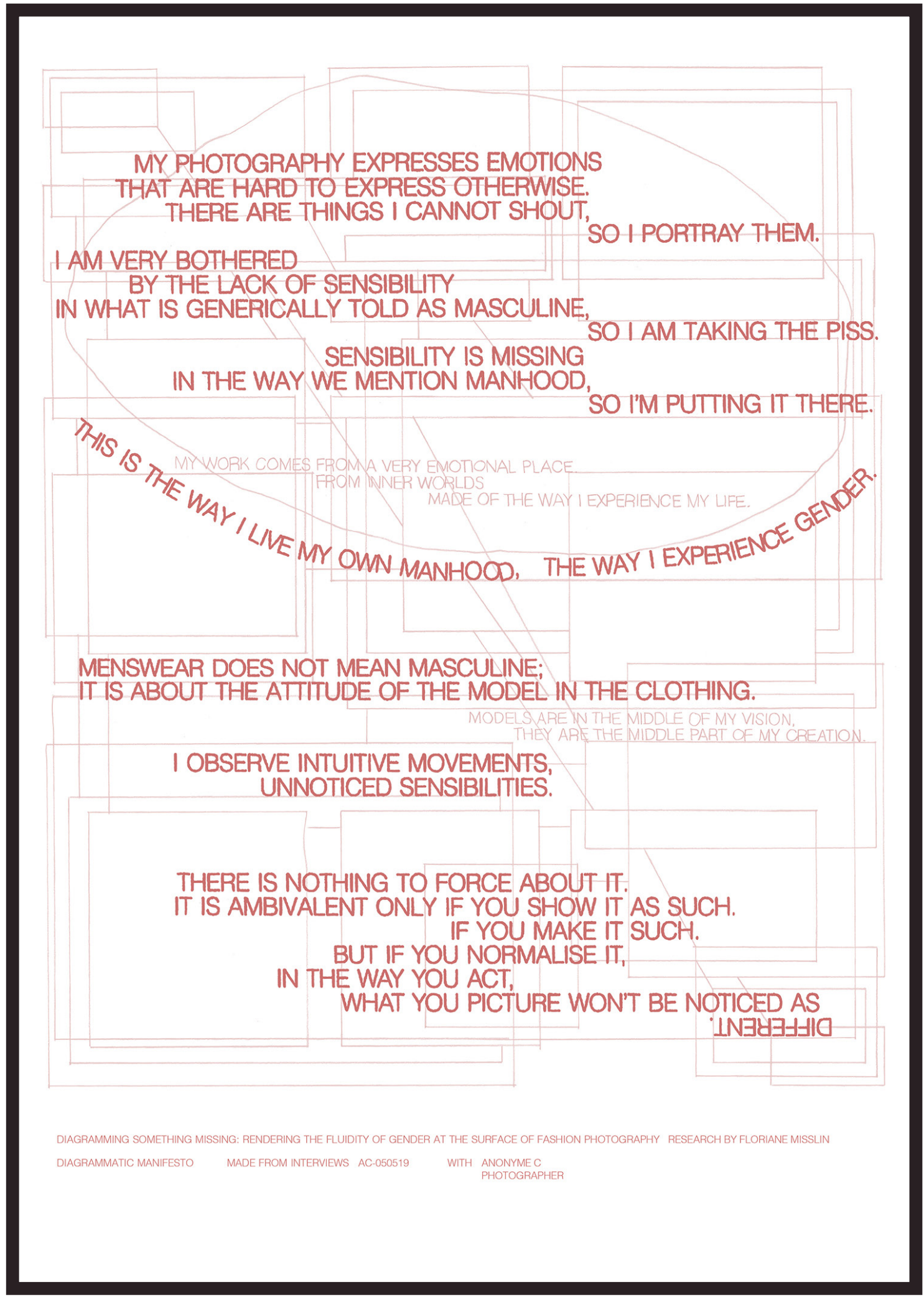

FIGURE 31 Diagrammatic Manifestos made with interviews with an anonymous fashion photographer 
I WORK WITH PEOPLE WHO ARE CLOSE TO ME.

THEY ARE PEOPLE WITH WHO

1 HAVE A LOT IN COMMON.

WE HAVE COMMON VISIONS,

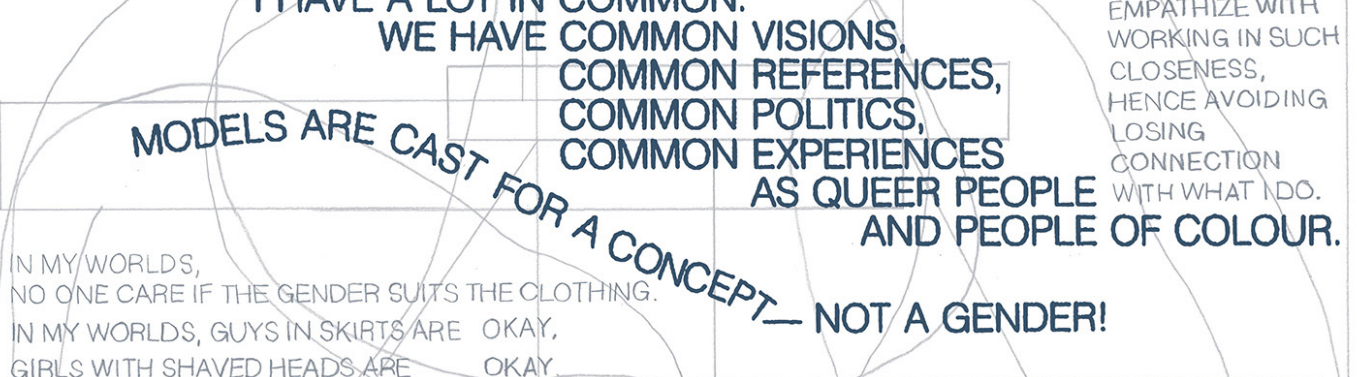

GIRLS WITH SHAVED HEADSARE

THE SHOOT BRINGS EVERYONE TOGETHER.

I CREATE SPACES OF EMPATHY AND INTIMACY, IN WHICH I ORIENT MY LENS ONTO THE MODELS. ON THE SURFACE OF THE PHOTOGRAPH IS

A GAME OF APPRECIATION CAPTURED

AND GAZING BETWEENME AND THEM.

IN MY LENS MATERIALISES THIS KINSHIP.

2 ON THE INTERFACE,

YSAE GENDER ECHOES IN OUR EXPERIENCES OF IT, ARE

IN OUR PLAY WITH IT,

IN THE WAY WE ADAPT IT' TO OUR DESIRES. 
MODELS ARE MY MUSES.

IN THE CONSTELLATION OF A PHOTOSHOOT, THE MODELS UNFOLD.

I TELL THEM;

THERE IS NO EXPECTATION TO GET ANYWHERE,

NO PRETENDING TO BE ANYONE BUT YOURSELF,

NO REPRODUCTION OF ANY IDEALS,

DO NOT ASSUME THAT YOU MUST TAKE

THE SHAPE OF OTHERS' ASSUMPTIONS.

THERE IS ENOUGH IN YOURSELF!

HOW, ALIGN, NINGS
NII

NTHIS CONSTELLATION,
REFLECTS MY OWN EVERYDAY

AS SOMEONE FLOATING

BETWEEN AND BEYOND POLARITIES.

I DISRUPT TO LET YOU GLIMPSE OTHER SCOPES,

I DISRUPT TO EXPOSE YOU TO DIMENSIONS OF

$$
\begin{aligned}
& \text { I WANT TO JOIN TY MAINSTREAM FLOW, } \\
& \text { AND REACH YOU FROM YOUR ORDINARY MAGAZINES. } \\
& \text { MY STORIES ARE ORDINARY STORIES. } \\
& \text { THE ORDINARY OF NON-BINARY PEOPLE. } \\
& \text { AN ORDINARY THAT IS ENOUGH FLU } \\
& \text { TO BE PART OF YOUR ORDINARY. }
\end{aligned}
$$




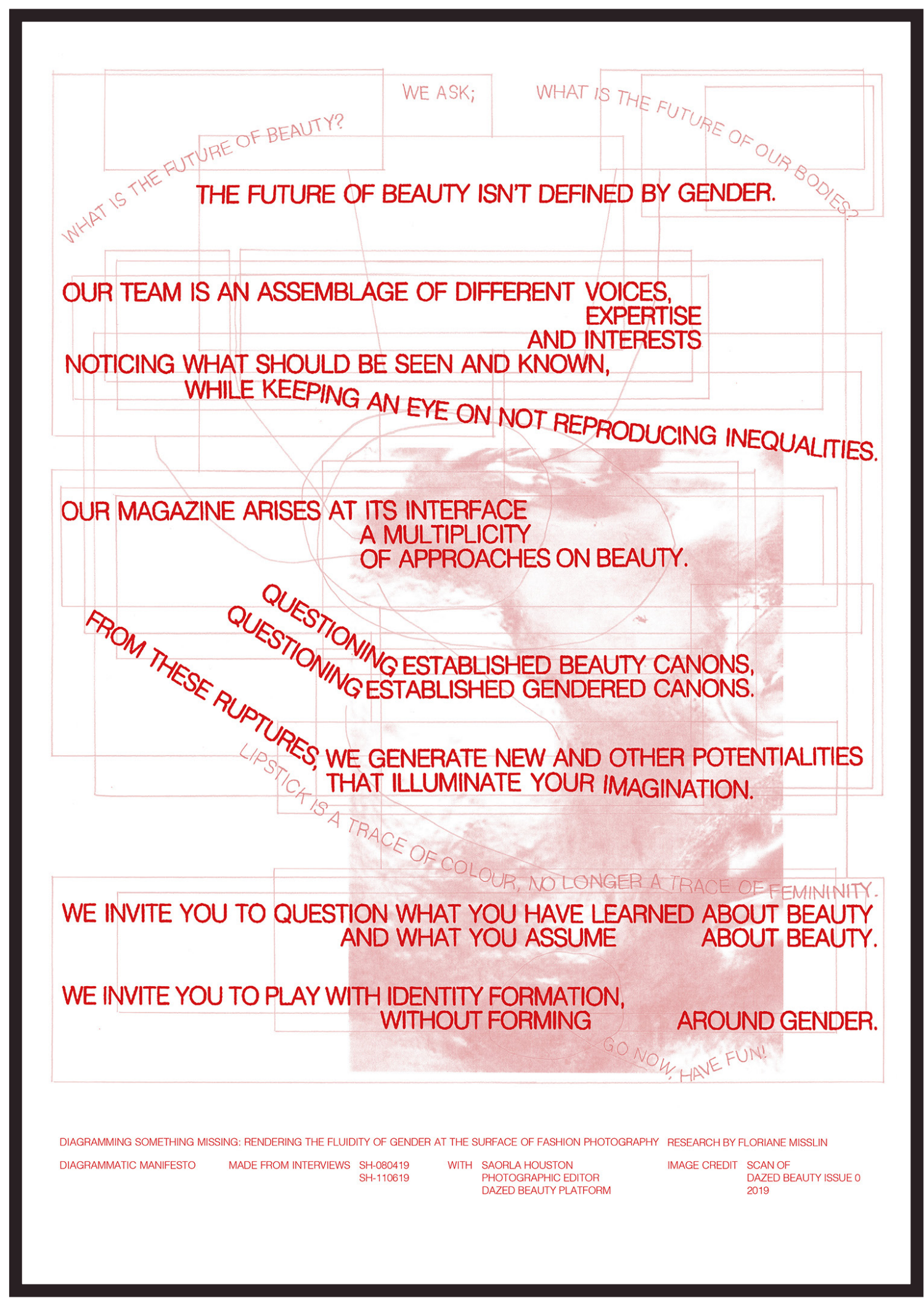


BRINGING ETHICAL AND SUSTAINABLE CLOTHING FURTHER, CONSIDER CONSUMERS AS EQUALS,

IS MAKING IT UNISEX! REGARDLESS OF THEIR GENDER! MY CLOTHING ARE MATERIAL GOODS

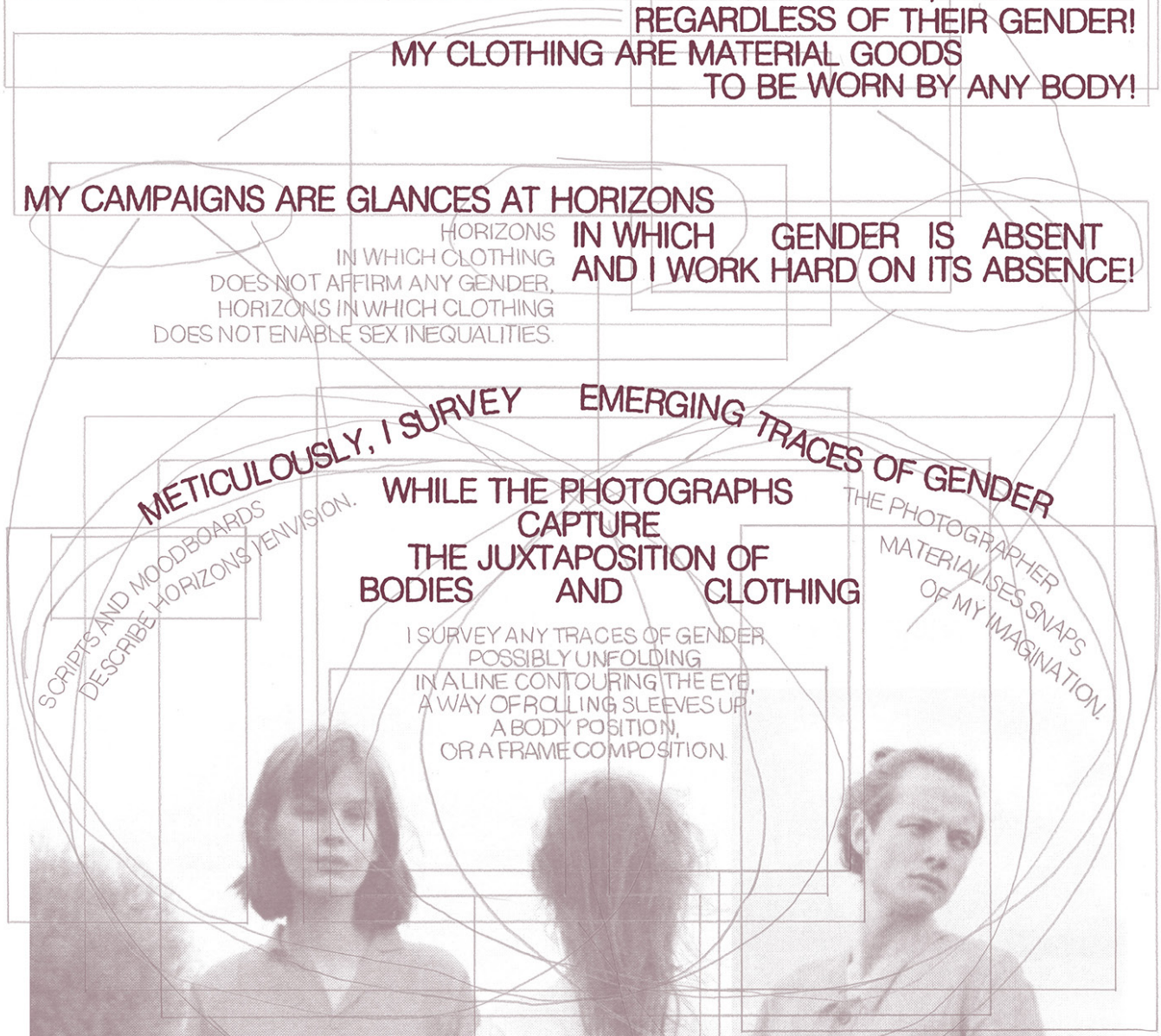

SILHOUETTES REMAIN AMBIGUOUS TO THEMSELVES AND TO YOURSELF, KEEPING THINGS UNKNOWN

$$
\text { BLURRY, HAZY, }
$$

LEAVING YOU SCOPE TO RELAY THESE HORIZONS

IN YOUR OWN IMAGINATION

AND FORMATION OF YOURSELF.

FIGURE 35 Diagrammatic Manifestos made with interviews with director of unisex clothing brand Lane FortyFive. 


\section{CONCLUSION}

In response to the expanding interest in fashion studies for interdisciplinary and creative methods (Barry, 2017; Granata; 2012; Jenss, 2016), this paper has proposed a live (Back and Puwar, 2012) and inventive (Lury and Wakeford, 2012) method for bringing attention to the personal and embodied experiences of gender through fashion. The project has approached research as a creative process and considered the political commitment of its method (Back, 2012; Back and Puwar, 2012). I have addressed how research methods can attend diverse, complex, and ambivalent descriptions of gender in order to contribute to more inclusive research on fashion and gender. I have thus proposed a methodology that acts as a reflective process through which researchers and participants work collaboratively to describe the personal and political motivations that drive gender fluid practices of fashion photography.

\section{In this way, the method has actively involved participants in the interpretation of their own lived experiences as well as how they are de- scribed in the public outcome of the research.}

The photographers, editors, and art directors I interviewed during this research signalled that the fluidity of gender as something missing in the fashion industry and the images it generates. The campaigns, look books, and editorials produced by the participants of this research intend to disrupt the divided markets of womenswear and menswear by showing the possibility of an otherwise: the production and consumption of fashion beyond binary understandings of gender. My attempt to empirically study the fluidity of gender has exposed the methodological concern of engaging in a subject that we mostly know through a binary ontology. For this reason, I designed a methodology to analyze the conditions in which relations diverge from - rather than converge to - the dominant ideals of femininity and masculinity. 
The method of the Diagrammatic Manifestos consists of a graphic reorganization of the qualitative data to expose the different ways each participant describes their relations to gender and how it affects the images they produce. As a result of this research, it is apparent that gender fluid practices of fashion photography can be defined as "a productive mode of exploring differences between norms and individual experiences by making this potentiality visible through commercial fashion imagery" (Misslin, 2020, p. 91).

With this research, I have identified certain restrictions that producers of fashion imagery face when taking a gender fluid approach. These are limitations that the fashion industry perpetuates to limit the production of discourses critical to its functioning (Titton, 2016). At the same time, this research has highlighted the creative solutions that originate from such limitations. Sadre-Orafai stated that fashion studies demystifies "the machination of the fashion industry and shows its 'rationality"' (2016, p. 104). With this project, situated at the intersection of sociology, fashion studies, and gender studies, I have worked to demystify the intricate relations between fashion and gender. The circulation of the Diagrammatic Manifestos intends to engage audiences in a questioning of how the fashion industry and its media systemize their relations to gender. Indeed, the visitors of the exhibition Snacks (see section IIE) reported that the manifestos made them aware of the complexities of detaching fashion from gender. 
Adkins, L., 2002. Reflexivity and the Politics of Qualitative Research, in: May, T. (Ed.), Qualitative Research in Action. SAGE Publications Ltd, London, pp. 349-374.

Aspers, P., 2001. A MARKET IN VOGUE Fashion photography in Sweden. European Societies 3, 1-22.

Aspers, P., Godart, F., 2013. Sociology of Fashion: Order and Change. Annual Review of Sociology 39, 171-192.

Back, L., 2012. Live Sociology: Social Research and Its Futures. Sociological Review 60, 18-39.

Back, L., Puwar, N., 2012. A Manifesto for Live Methods: Provocations and Capacities. Sociological Review 60.

Barry, B., 2017. Enclothed Knowledge: The Fashion Show as a Method of Dissemination in Arts-Informed Research. In Forum Qualitative Sozialforschung / Forum: Qualitative Social Research 18.

Barthes, R., 1967. The Fashion System. University of California Press: Berkeley.

Budgeon, S., 2013. The Dynamics of Gender Hegemony: Femininities, Masculinities and Social Change. Sociology 48, 317-334.

Butler, J.P., 1990. Gender Trouble: Feminism and the Subversion of Identity. Routledge.

Colebrook, C., 2004. Postmodernism Is a Humanism: Deleuze and Equivocity. Women: A Cultural Review 15, 283-307.

Crane, D., 1999. Gender and Hegemony in Fashion Magazines: Women's Interpretations of Fashion Photographs. The Sociological Quarterly 40, 541-563.

Crane, D., Bovone, L., 2006. Approaches to Material Culture: The Sociology of Fashion and Clothing. Poetics 34, 319-333.

Deleuze, G., Guattari, F., 1987. A Thousand Plateaus: Capitalism and Schizophrenia. London and New York: Continuum, London.

Entwistle, J., Mears, A., 2013. Gender on Display: Peformativity in Fashion Modelling. Cultural Sociology 7, 320-335.

Godart, F.C., Mears, A., 2009. How Do Cultural Producers Make Creative Decisions? Lessons from the Catwalk. Social Forces 88, 671-692.

Granata, F., 2012. Fashion Studies In-between: A Methodological Case Study and an Inquiry into the State of Fashion Studies. Fashion Theory 16, 67-82. preting Qualitative Data. Qualitative Research 13, 562-577. 
Jenss, H., 2016. Fashion Studies: Research Methods, Sites, and Practices. London: Bloomsbury Academic.

Jobling, P., 1999. Fashion Spreads: Word and Image in Fashion Photography Since 1980. Berg.

Kaiser, S.B., Green, D.N., 2016. Mixing Qualitative and Quantitative Methods in Fashion Studies: Philosophical Underpinnings and Multiple Masculinities., in: Jenss, H. (Ed.), Fashion Studies: Research Methods, Sites, and Practices. London: Bloomsbury Academic, pp. 160-180.

Law, J., Ruppert, E., Savage, M., 2011. The Double Social Life of Methods. Centre for Research on Socio-Cultural Change (CRESC), Working Paper No 95.

Linstead, A., Brewis, J., 2004. Beyond Boundaries: Towards Fluidity in Theorizing and Practice. Gender, Work and Organization 11, 355-362.

Linstead, S., Pullen, A., 2006. Gender as Multiplicity: Desire, Displacement, Difference and Dispersion. Human Relations 59, 1287-1310.

Lury, C., Wakeford, N. (Eds.), 2012. Inventive Methods: The Happening of the Social. Routledge.

Luvaas, B., 2016. Street Style: An Ethnography of Fashion Blogging. London: Bloomsbury Academic.

Lynge-Jorlén, A., 2016. Editorial Styling: Between Creative Solutions and Economic Restrictions. Fashion Practice 8, 85-97.

Lynge-Jorlén, A., 2012. Between Frivolity and Art: Contemporary Niche Fashion Magazines. Fashion Theory 16, 7-28.

MacLure, M., 2013. Classification or Wonder: Coding as an Analytic Practice in Qualitative Research, in: Coleman, R., Ringrose, J. (Eds.), Deleuze and Research Methodologies. Edinburgh University Press, pp. 164-177.

Moeran, B., 2006. More Than Just a Fashion Magazine. Current Sociology 54, 725-744.

Misslin, F., 2020. Diagramming Fluidity: Designing a Research Method. Onomatopee.

Muñoz, J., 2009. Cruising Utopia: The Then and There of Queer Futurity. New York University Press.

Ruggerone, L., 2006. The Simulated (fictitious) Body: The Production of Women's Images in Fashion Photography. Poetics 34, 354-369.

Sadre-Orafai, S., 2016. Recasting Fashion Image Production: An Ethnographic and Practice-Based Approach to Studying Bodies as Media, in: Jenss, H. (Ed.), Fashion Studies: Research Methods, Sites, and Practices. Bloomsbury Academic, pp. 101-116 
Titton, M., 2016. Fashion Criticism Unravelled: A Sociological Critique of Criticism in Fashion Media. International Journal of Fashion Studies 3, 209-223.

Von Busch, O., 2016. Action! Or, Exploring Diffractive Methods for Fashion Research, in: Jenss, H. (Ed.), Fashion Studies: Research Methods, Sites, and Practices. London: Bloomsbury Academic, pp. 181-197.

Woodward, S., 2008. Digital Photography and Research Relationships: Capturing the Fashion Moment. Sociology 42, 857-872.

Zdebik, J., 2012. Deleuze and the Diagram: Aesthetic Threads in Visual Organization. Continuum. 


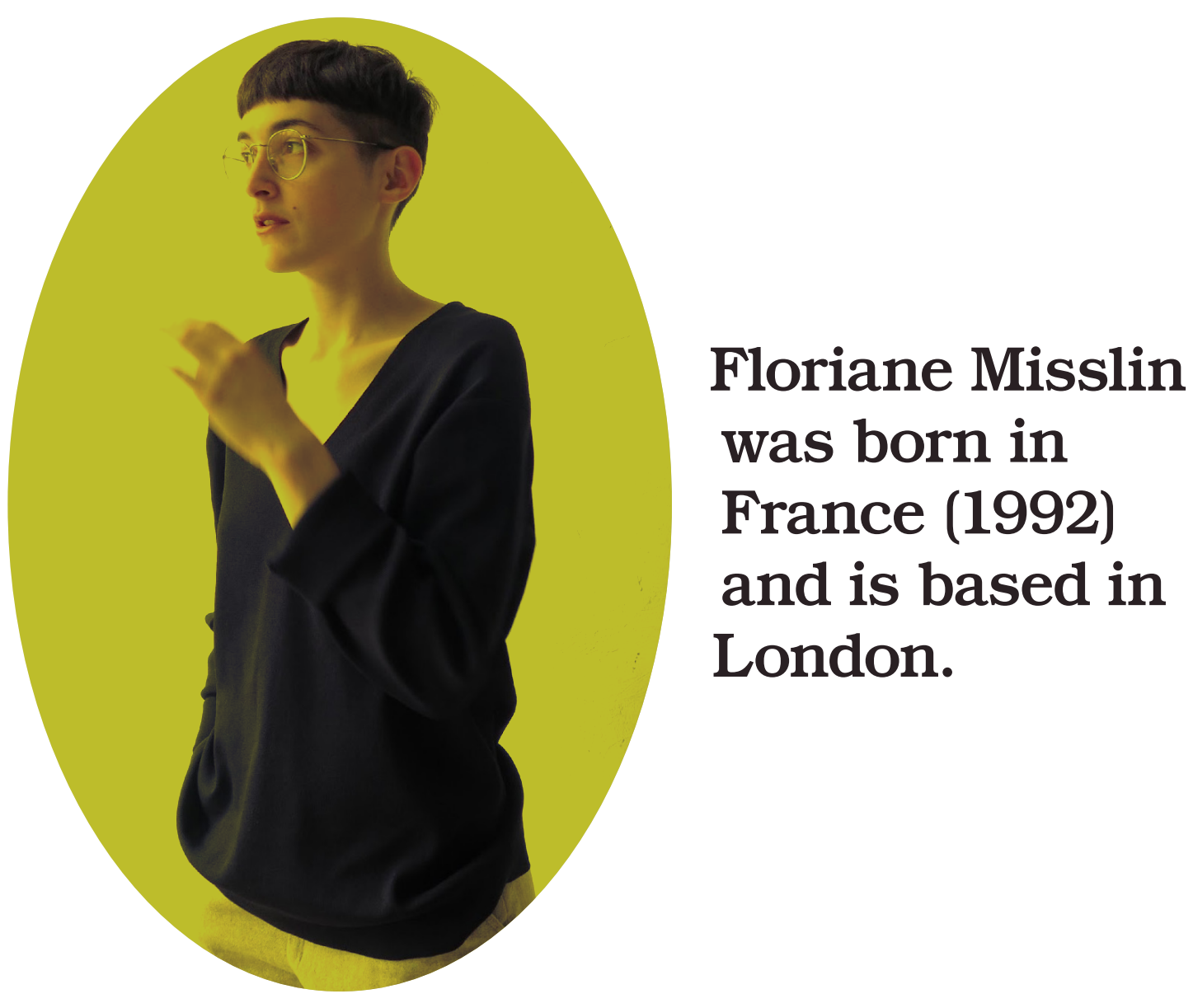

She has studied fashion design in Paris before moving to the Netherlands to take a more critical approach to design at the Design Academy Eindhoven. She continued with a Master in Visual Sociology at Goldsmiths University of London and started a PhD in this same discipline in September 2020 to continue creatively exploring research methods. Her practice resides somewhere between visual and critical design, fashion and gender studies, sociology, and art. In her research and educational practice, she designs methodologies that provide live and interactive ways to explore the entanglements between bodies, visual culture, and their relation to gender. Website: florianemisslin.com.

\section{ARTICLE CITATION}

Misslin, Floriane. "Diagrammatic Manifestos." Fashion Studies, vol. 3, no. 1, pp. 1-46, https://www.fashionstudies.ca/diagrammatic-manifestos, https://doi. org/10.38055/FS030106. 


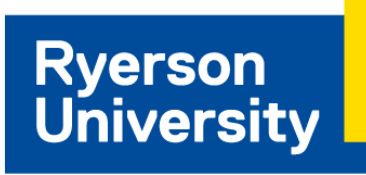

Fashion

Faculty of Communication

\& Design

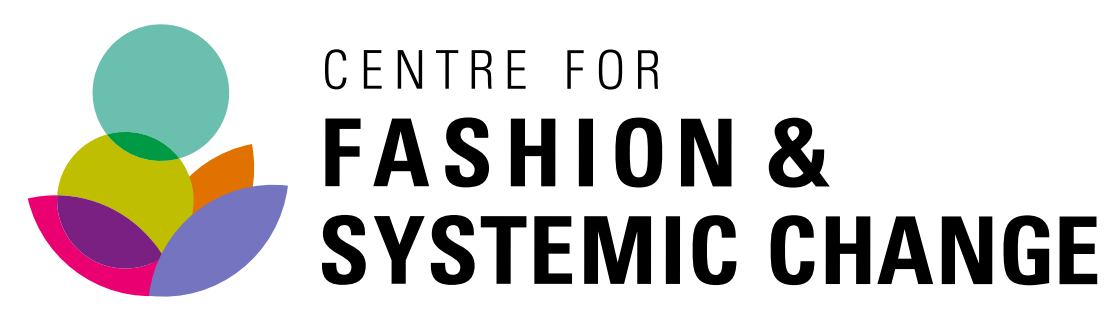

Frows $\mathrm{SH} / \mathrm{ON}$

\section{ISSN 2371-3453}

Copyright (C) 2020 Fashion Studies - All Rights Reserved

Creative Commons Attribution-NonCommercial-NoDerivatives 4.0 International (CC BYNC-ND 4.0) license (see: https://creativecommons.org/licenses/by-nc-nd/4.0/) 